This is the final peer-reviewed accepted manuscript of:

Michele Bianchi, Lisa Branchini, Nicola Casari, Andrea De Pascale, Francesco Melino, Saverio Ottaviano, Michele Pinelli, Pier Ruggero Spina, Alessio Suman

Experimental Analysis of a Micro-ORC Driven by Piston Expander for Low-Grade Heat Recovery

Applied Thermal Engineering, Volume 148, 2019, pp. 1278-1291

The final published version is available online at:

https://doi.org/10.1016/i.applthermaleng.2018.12.019

(C)2019. This manuscript version is made available under the Creative Commons AttributionNonCommercial-NoDerivs (CC BY-NC-ND) 4.0 International License

(http://creativecommons.org/licenses/by-nc-nd/4.0/) 


\title{
EXPERIMENTAL ANALYSIS OF A MICRO-ORC DRIVEN BY PISTON EXPANDER FOR LOW-GRADE HEAT RECOVERY
}

\author{
Bianchi M. ${ }^{a}$, Branchini L. ${ }^{a}$, Casari N. ${ }^{b}$, De Pascale A. ${ }^{a}$, Melino F. ${ }^{a}$, Ottaviano S. ${ }^{a}$, Pinelli M. ${ }^{b}$, Spina P.R. ${ }^{b}$, \\ Suman A. ${ }^{b}$ \\ ${ }^{a}$ Università di Bologna - DIN, Viale del Risorgimento 2, 40136, Bologna, Italy \\ ${ }^{b}$ Università di Ferrara- ENDIF, via Saragat 1, 44122, Ferrara, Italy
}

*corresponding author, e-mail: lisa.branchini2@unibo.it, phone: +39-051-2093314

\begin{abstract}
In this paper, a full experimental characterization of a micro-scale ORC system is presented. The facility under investigation is driven by a piston expander prototype, made of three cylinders arranged radially around the drive shaft. The system is rated for a thermal input around $30 \mathrm{~kW}$, being suitable for residential, tertiary sector or small industry applications. It is conceived for exploiting low temperature heat sources, such as solar collectors, biomass boilers, geothermal energy or waste heat streams. The facility was provided with an electric boiler as heat source, which warms water up to $90{ }^{\circ} \mathrm{C}$, and cold water at ambient temperature as heat sink. A test campaign was performed varying the hot source temperature and the organic fluid feed pump velocity, in order to characterize the system behavior at different off-design working conditions. The electric consumption of the ORC feed pump was measured, in order to quantify the actual impact of the auxiliaries on the overall efficiency. Moreover, the number of electric loads connected to the generator was varied, changing the equivalent phase impedance value, for evaluating the effect on the expander rotating speed and power output.

The experimental analysis demonstrated that small reciprocating expander is suitable for exploiting low enthalpy heat sources, with quite good performances compared to other architectures like scroll and screw expanders, more applied within low temperature sources. The results show that the gross electric power output varied between $250 \mathrm{~W}$ and $1150 \mathrm{~W}$, depending on the expander speed and on the number of electric loads activated. The expander total efficiency showed a barely constant trend around $40 \%$. The pump total efficiency varied between $10 \%$ and $20 \%$, increasing with the pump rotational speed. The maximum ORC gross and net efficiency were $4.5 \%$ and $2.2 \%$ respectively, confirming that the auxiliaries impact cannot be considered negligible in such type of systems.
\end{abstract}

Keywords: Micro Organic Rankine cycle; low grade heat source; experimental; piston expander; pump consumption. 


\begin{tabular}{|c|c|c|c|}
\hline \multicolumn{2}{|c|}{ Nomenclature } & \multicolumn{2}{|c|}{ Greek letters } \\
\hline AI & Analog input & $\eta$ & Efficiency [\%] \\
\hline BWR & Back Work Ratio [\%] & $\rho$ & Density $\left[\mathrm{kg} / \mathrm{m}^{3}\right]$ \\
\hline CHP & Combined Heat and Power & $\sigma$ & Standard deviation (referred to uncertainty) \\
\hline & Error & $\tau$ & Terminal temperature difference $\left[{ }^{\circ} \mathrm{C}\right]$ \\
\hline & Filling Factor & \multicolumn{2}{|c|}{ Subscripts } \\
\hline FPGA & Field Programmable Gate Array & cold & Cold water supply \\
\hline FS & Full Scale & cond & Condensation \\
\hline$h$ & Enthalpy $[\mathrm{kJ} / \mathrm{kg}]$ & & Electric \\
\hline$I / O$ & Input/Output & ev & Evaporation \\
\hline & Internal Combustion Engine & $\exp$ & Expander \\
\hline$\dot{m}$ & Mass flow rate $[\mathrm{kg} / \mathrm{s}]$ & $\mathrm{F}$ & Furnace \\
\hline$N$ & Rotational speed [rpm] & gross & Gross \\
\hline ORC & Organic Rankine Cycle & hot & Hot water supply \\
\hline$p$ & Pressure [bar] & is & Isentropic \\
\hline PCB & Printed Circuit Board & LIQ & Liquid phase (saturation) \\
\hline$\dot{Q}$ & Thermal power $[\mathrm{kW}]$ & net & Net \\
\hline$R$ & Steady state index $[-]$ & $\mathrm{p}$ & referred to pressure \\
\hline $\mathrm{RV}$ & Reading value & PLS & Primary Laboratory Standard \\
\hline$T$ & Temperature $\left[{ }^{\circ} \mathrm{C}\right]$ & pp & Pump \\
\hline$t_{s s}$ & Minimum duration for steady-state interval [s] & & 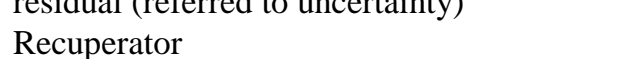 \\
\hline$U$ & uncertainty & $\operatorname{rrc}$ & Ideal reversible cycle \\
\hline$\dot{v}$ & Specific volume $\left[\mathrm{m}^{3} / \mathrm{kg}\right]$ & suc & Suction \\
\hline & Volumetric flow rate $[1 / \mathrm{s}]$ & $\mathrm{SC}$ & Sub-cooling \\
\hline & Power [W] & SH & Superheating \\
\hline & & $\mathrm{T}$ & referred to temperature \\
\hline & & & thermodynamic (referred to power) \\
\hline & & VAP & Vapor phase (saturation) \\
\hline
\end{tabular}

\section{INTRODUCTION}

\section{Context and state-of-the-art}

New heat conversion technologies are currently achieving substantial interest both on industrial and research side. The Organic Rankine Cycle (ORC) is well suited for these applications mainly due to its ability to recover low-grade heat and, at the same time, the possibility to be implemented as distributed small-size generator for decentralized end-users' energy production. Combined heat and Power (CHP) applications of ORC can be considered as alternative to traditional systems, in terms of energy saving and environmental conservation. As pointed out in [1], small-scale and micro-scale CHP systems are particularly suitable for applications in commercial buildings (such as hospitals, schools, industrial premises, office building blocks) and domestic buildings of single or multifamily dwelling houses. Small-scale and micro-scale CHP systems can help to meet a number of energy and social policy aims, including the reduction in greenhouse gas emissions, improved energy security, investment saving resulted from the omission of the electricity transmission and distribution network and the potentially reduced energy cost to consumer.

Thus, micro and small-scale ORC technologies are undergoing a rapid development, stating on the market as emerging and promising device to exploit low grade heat sources [1]. Many experimental small-scale ORC realizations are described and analyzed in literature. Landelle et al. [2] summarize in a comprehensive database data of ORC facilities available in the experimental state-of-the-art analysis. The database allows to evaluate ORC overall performances, in order to perform a fair comparison between realizations. The survey results show that, in the power range between $0.1 \mathrm{~kW}$ up to $10 \mathrm{~kW}$, the most 
diffused applications are solar and waste heat recovery, while the coupling with biomass is less common. Moreover, the results confirm that the ORC achievable performances are strictly related to the operating conditions (hot and cold temperature levels), the selection of the most appropriate working fluid, the choice and sizing of the expansion machine.

In particular, the selection of the expander depends on several criteria: pressure ratio, thermodynamic performance, reliability, compactness [3]. However, in micro-power applications, economic, technical and operational constrains may often prove to be more important than efficiency. Also noise, vibration and dimensions aspects should be taken into account. Due to all these variables and limitations, the optimal technology and layout of expanders for micro-scale ORC systems are not detected yet. Positive displacement expanders, which are generally preferable to turbomachines for systems of power lower than $150 \mathrm{~kW}$, have not achieved the technical maturity yet, and their architectures mostly derive from displacement compressors from HVAC\&R and compressed air industries. When the difference between the temperatures of the heat source and of the cold sink is relatively low, also the expansion ratio available at the expander is limited. This condition is suitable for the scroll architecture, characterized by a low built-in volume ratio [4]. Most studies in literature refer to scroll compressors converted to expander, while in some cases original manufacturer machines or prototypes were adopted; for example, Abadi et. al [5], investigated a $1 \mathrm{~kW}$ scroll expander developed by the company Air Squared, adopting a zeotropic mixture of R245fa and R134a as working fluid; they achieved a power output close to $1.2 \mathrm{~kW}$ with an expansion ratio of 3.3, with a maximum net cycle efficiency close to $6 \%$. Ziviani et al. [6] tested a $5 \mathrm{~kW}$ open-drive scroll expander with R245fa with a hot source temperature equal to $85^{\circ} \mathrm{C}$ and $110^{\circ} \mathrm{C}$, varying the $\mathrm{ORC}$ mass flow rate; they achieved the maximum power of $3.75 \mathrm{~kW}$ at 2500 rpm, with an isentropic efficiency equal to $55 \%$. Ayachi et al. [7] performed a study on an ORC system driven by a prototype scroll expander, using R245fa superheated vapor as working fluid; the expander they tested produced a power output variable between $0.2 \mathrm{~kW}$ and $3 \mathrm{~kW}$, with an expansion ratio between 2 and 3.8. In [8] Yun et al. implemented a test facility with two scroll expanders (derived from air compressors) running in parallel. They obtained a maximum power output equal to $1.7 \mathrm{~kW}$ and $3.4 \mathrm{~kW}$ for single and dual-mode respectively, for pressure ratios between 2.6 and 6.5 . The maximum isentropic efficiency and cycle efficiency was $62 \%$ and $7.5 \%$ respectively, regardless of the operating mode. The screw model is often adopted as well, both in the single and double screw architecture, adapting to expansion ratios higher than scroll expander. Ziviani et al. [9] characterized the performance of a single screw expander modified from an air compressor, with two working fluids (R245fa and the mixture SES36). They reported a maximum power output close to $8 \mathrm{~kW}$ and a maximum isentropic efficiency close to $60 \%$, while the ORC net efficiency varied between $2 \%$ and $9 \%$. Reciprocating piston expander is less applied in kW-scale systems with low heat source temperature (thus lower available expansion ratio) because it is characterized by higher built-in volume ratio. Unlike scroll and screw models, the piston expander requires valves for suction and discharge, involving more complexity in the machine design and operation. Most examples are related to the swash-plate configuration in waste heat recovery from internal combustion engine (ICE) application: for instance, the authors of [10] presented an experimental study on a three piston swash-plate machine delivered by Exoes, reporting a mechanical power between 0.3 and $1 \mathrm{~kW}$ with an expansion ratio between 9 and 12.5. Oudkerk et al [11] presented an experimental characterization of an ORC system driven by a swash-plate expander, producing a mechanical output of $0.3-2 \mathrm{~kW}$, with an expander isentropic efficiency variable between $33 \%$ and $53 \%$. Dumont et al. [12] performed an experimental comparison on the same test bench between four models of volumetric expander (piston, scroll, screw and roots expander) in the kW-scale. The aim of their study was to facilitate the selection of the expansion machine in small scale facilities, but the performance they achieved were not optimized since the working conditions were not the most suitable for each machine model. Other studies $[13,14]$ describe the free piston expander-linear generator as solution for ORC waste heat recovery from ICE, achieving a maximum power output close 
to $20 \mathrm{~W}$ and to $100 \mathrm{~W}$ respectively. A comprehensive survey of experimental data on micro-scale ORC systems has been recently published by Park et al. [15]; they collected information from more than 200 references to compare working conditions and performances in terms of the common adopted indicators (power output, expander isentropic efficiency, BWR, cycle efficiency, etc.).

One more critical aspect of micro-ORC systems regards the feed pump selection and dimensioning [4]. The pump operation indeed, has a not negligible impact on the net power output and on the global efficiency of the system. The back work ratio (BWR), defined as the ratio between the pump absorbed power and the expander output, can be considerable if compared to the typical value for large scale and high temperature ORCs (between $1 \%$ and $10 \%$ ) and for steam Rankine cycle (0.1 - $2 \%$ ); in fact, the BWR increases if the critical temperature of the working fluid is low, and becomes very high when the evaporation temperature is close to the critical temperature. In some cases with very low power output [16-17], the authors opted for a solution with pump-less ORC system to avoid the penalization due to the pump consumption. The pump total efficiency becomes therefore a more crucial parameter on lowest size applications (gross produced power $<10 \mathrm{~kW}$ ), for which the pump consumption can account for a large fraction of the expander generated power. On systems of such size, experimental data on feed pump performance are not frequently and in detail presented in literature. In modeling studies, the pump efficiency is taken between 65 and $85 \%$, but these values are based on pumps manufacturer data and often do not consider the off-design operation performance and the electric motor efficiency, which can be lower than expected especially if the motor is oversized [4]. For example, Quoilin et al. [18] achieved a pump total efficiency of $25 \%$, while Reid et al. [19] report a value of $7 \%$, both in kW-scale ORC units. In [20], Landelle et al. collected from literature several ORC pump efficiency data as function of the hydraulic power. They observed that the average efficiency is around $35 \%$ for small ORC power plants, but it is not specified if the electric losses are always included into the efficiency calculation.

In the experimental research, the methodology applied for the data analysis is of primary importance, to produce reliable and repeatable results that can then be compared to other cases with similar features presented in literature. The first step of the data processing is the detection of the steady-state operating points achieved during the experimental tests. Several methods have been proposed in literature, mainly applied in process or chemical engineering [21-23]; Woodland et al. [24] suggested a standard for ORC systems, which consists in considering the variations of the variables trend on a manually identified steady-state time window, through the comparison between simple average values taken at different time. Lecompte [25] applied a steady-state algorithm (derived from the one implemented by Kim et al. on an air conditioner [26]) on the experimental data of a $11 \mathrm{~kW}$ ORC system, based on the calculation of the moving standard deviation of the main process variables. Li et al. [27] adopted a similar method on their dynamic analysis of a transcritical $\mathrm{CO}_{2}$ power cycle for heat recovery from a heavy-duty diesel engine; they computed the absolute deviation on a moving time window equal to 5 seconds and compared it to pre-set thresholds. All the above-mentioned approaches are suitable for the post-processing application. The on-line implementation of a steady-state algorithm presents the advantage of improving the control during the test operations and of providing better sensitivity to the dynamic phenomena. On the other hand, the duration of the tests and the efforts for the data post-processing can be significantly reduced.

\section{Contribution of this paper}

The aim of this paper is to provide a full characterization of a $\mathrm{kW}$-scale test facility, conceived for exploiting low-enthalpy heat sources in micro-cogenerative applications for residential, small industry or tertiary sectors. The Authors' opinion is that the improvement and the deployment of low-temperature heat conversion technologies is one of the key solutions contributing to primary energy savings worldwide and to the reduction of global emissions of pollutants and greenhouse gases. 
The novelty of the system presented is the expansion machine, which is the radial piston prototype already introduced in [28]. To the Authors' knowledge, reciprocating expanders with radial architecture are quite uncommon in the dedicated literature, especially with heat source temperature lower than $100^{\circ} \mathrm{C}$. Hence, the analysis presented in this study intends to help to understand potentialities, criticalities and possible improvements of power systems with such characteristics, providing a full set of experimental results that can be compared to other more conventional systems, in terms of working conditions and performance. With respect to the mentioned previous work of the Authors, the operating conditions investigated were extended, and a deep analysis was conducted on the experimental data, obtaining detailed operation and performance maps of the ORC system, that are presented in this paper. Moreover, the analysis of the expander performance was carried out changing the number of electrical loads connected to the generator, focusing on the effect on the expander rotating speed and power output. On the other hand, accurate experimental data on the circulation gear pump implemented on this test bench are provided: the actual power absorbed by the pump electric motor was measured, instant by instant, allowing to evaluate the pump total efficiency and the real net power output of the ORC system. The steady-state detection algorithm called R-test was tested online and the results compared to the post-processing applicable method. The faster calculation compared to the other mentioned methodologies makes the R-test a helpful tool for the comprehension of the dynamic phenomena and for the system control, if opportunely calibrated. A detailed analysis of the global uncertainty related to the performance evaluation was conducted too; the uncertainty contributions of the single components of the acquisition system have been estimated, considering the accuracy of the different sensors (including the signal cables), and the error introduced by the acquisition devices (responsible for analogical/digital conversion, cold joint compensation, etc.).

\section{MICRO-ORC AND TEST BENCH DESCRIPTION}

A small-scale test rig was developed at the Laboratory of the University of Bologna for investigating the global performance of the prototypal micro-ORC energy system. The test system, presented in Figure 1, consists of three loops, namely the hot source, the cooling system and the ORC circuit. In the hot source loop, the thermal input is provided by a 500 liters electric water boiler, rated for a thermal power input of $32 \mathrm{~kW}$. The variable flow centrifugal pump P2 circulates water with flow rate values ranging between $1.0 \mathrm{l} / \mathrm{s}$ and $2.6 \mathrm{l} / \mathrm{s}$. The hot water temperature, controlled switching on/off the electro-resistances of the boiler, is regulated between $50{ }^{\circ} \mathrm{C}$ and $90{ }^{\circ} \mathrm{C}$ to reproduce low grade heat sources. The cooling system is made with cold water extracted from a well by pump P3 and stored in a 300 liters tank, from which it is circulated to the condenser circuit by pump P1. Cooling water temperature, as it has been observed, is affected by ambient conditions, varying between $16{ }^{\circ} \mathrm{C}$ in winter and $25^{\circ} \mathrm{C}$ in summer. Cold water flow rate can be regulated by means of P1 pump between $1.0 \mathrm{l} / \mathrm{s}$ and $2.8 \mathrm{l} / \mathrm{s}$.

Focusing on the ORC circuit, it is based on a recuperative configuration and it operates with R134a as working fluid in a total charge between $12 \mathrm{~kg}$ and $13 \mathrm{~kg}$. The lubricating oil for the rotating parts of the ORC pump and expander is mixed with the working fluid, in a fraction between $3 \%$ and $6 \%$. 


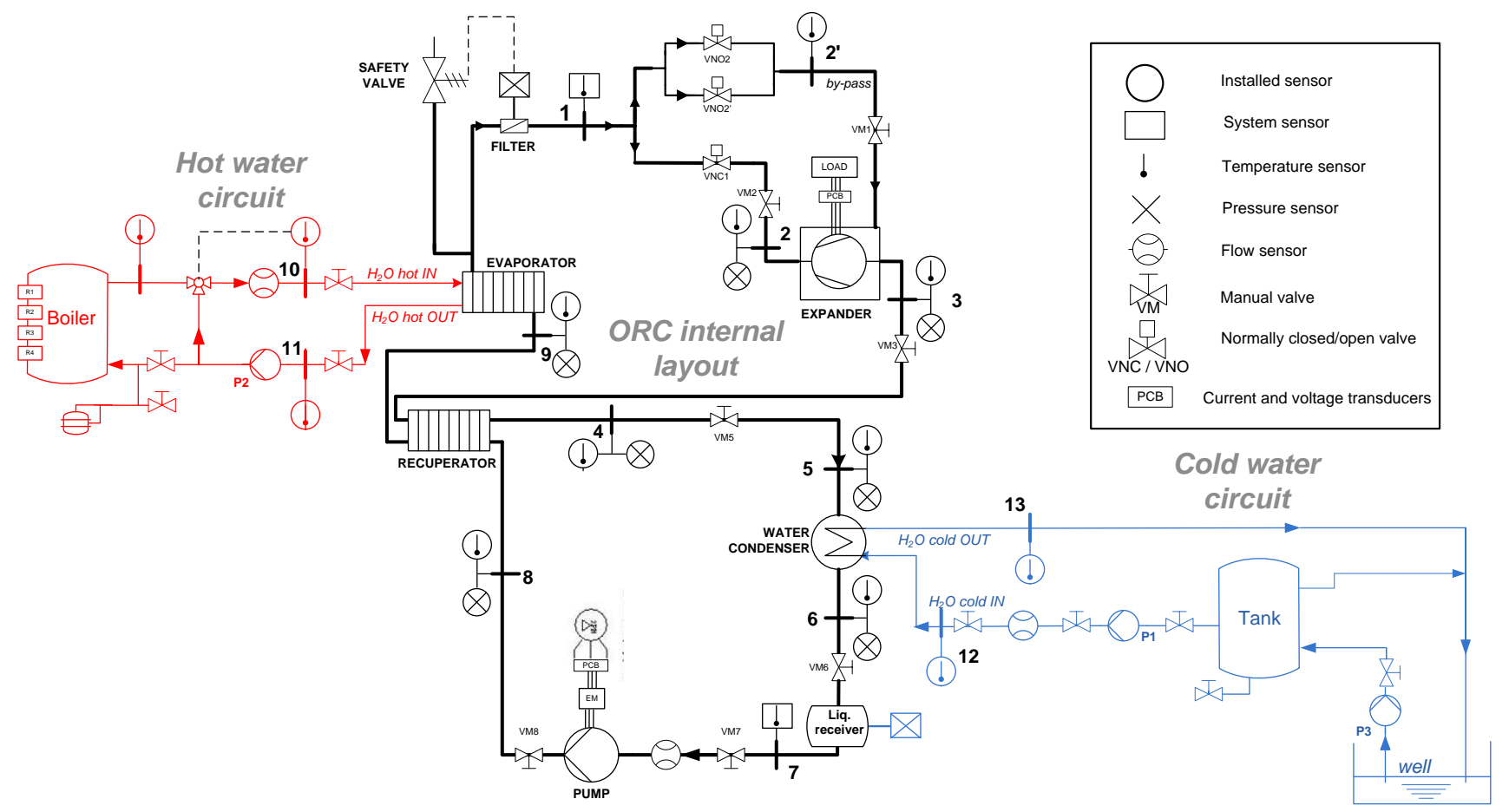

Figure 1 - Schematic of the test bench layout

The ORC main components, shown in Fig. 1, are:

i) the evaporator: a brazed plate heat exchanger with 64 plates; it recovers heat from the hot water source to produce superheated organic fluid vapor; ii) the expander is a prototype designed and developed by the company StarEngine (Figure 2 ); it is a reciprocating model, made of three radial cylinders placed at $120^{\circ}$ with a total displacement equal to $230 \mathrm{~cm}^{3}$; the three pistons move the same crankshaft with a phase difference equal to $120^{\circ}$, while the expander admission and discharge valves are rotary valves, driven by the crankshaft rotation (more information on patent document [29]). The expander is directly coupled to a permanent magnets electric generator in a hermetical sealed case. Since no transmission is interposed, expander and generator work at the same rotational speed. The external surface of the machine has been thermally insulated by means of mineral wool panels, in order to reduce heat transfer losses, which have been demonstrated not negligible in analogue applications [30]; iii) the recuperator: a plate heat exchanger with 19 elements. It recovers residual heat from the expander outlet stream to preheat the liquid prior to the evaporator inlet, in order to reduce the thermal input required by the system and to improve the overall cycle efficiency; iv) the condenser: a shell and tube heat exchanger; it uses cold water extracted from the well; v) the liquid receiver: a 19 I tank placed between the condenser and the recirculation pump; vi) the organic fluid recirculation pump is an external gear pump realized by StarEngine; the pump is directly driven by a three-phase motor, operated with variable speed by means of an inverter, in order to control the mass flow of R134a flowing through the cycle; vi) the electrical load connected to the generator is made of five pure resistive loads, connected in parallel between them and in delta with the generator output three-phase line. Each load is composed by three light bulbs with a nominal power of $200 \mathrm{~W}$ per bulb. Every load is provided with a separate switch, thus the nominal power absorbable by the resistive load is adjustable between a minimum of $600 \mathrm{~W}$ ( 1 load activated) and a maximum of $3000 \mathrm{~W}$ ( 5 loads activated), corresponding to the nominal ORC power output. Changing the number of loads switched-on will vary the nominal equivalent load impedance of each phase, which is maximum for only 1 load activated ( $288 \Omega$ ), then is halved for 2 loads, divided by three for 3 loads etc., down to the minimum value of $58 \Omega$ for the all in-parallel loads switched-on. The load configuration does not allow to set the generator 
rotational speed nor the load torque, thus the expander shaft is free to achieve the equilibrium between the generator torque and the load resistance.
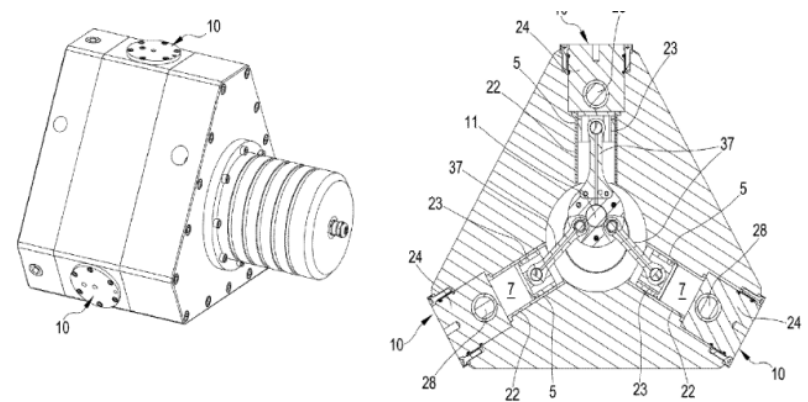

Figure 2- StarEngine piston expander prototype [29]

Figure 1 also shows the presence of several manual valves (VM) installed for inspection and in case of breakage; a normally closed valve (VNC1) and two normally open valves (VNO2, VNO2') are also installed for the ORC startup operation, when the fluid flows through the external casing of the expander (branch 1-2'), by-passing the expander cylinders (branch 1-2). This procedure allows, on one hand, to achieve the desired condition of superheating, avoiding potential liquid drops in the expander, on the other to increase the temperature of the expander surfaces, preventing thermal stresses on the machine. When the set point temperature is reached at the expander inlet $\left(2^{\prime}\right)$, the VNC1 valve can be opened, admitting the fluid inside the cylinders and activating the expander. Finally, a safety valve is installed at the outlet of the evaporator to interrupt the operation in case of unexpected overpressure (max pressure is set at 26 bar).

Figure 3 shows the micro-ORC prototype under investigation and a three-dimensional sketch. The total footprint area is equal to $80 \times 85 \mathrm{~cm}$.
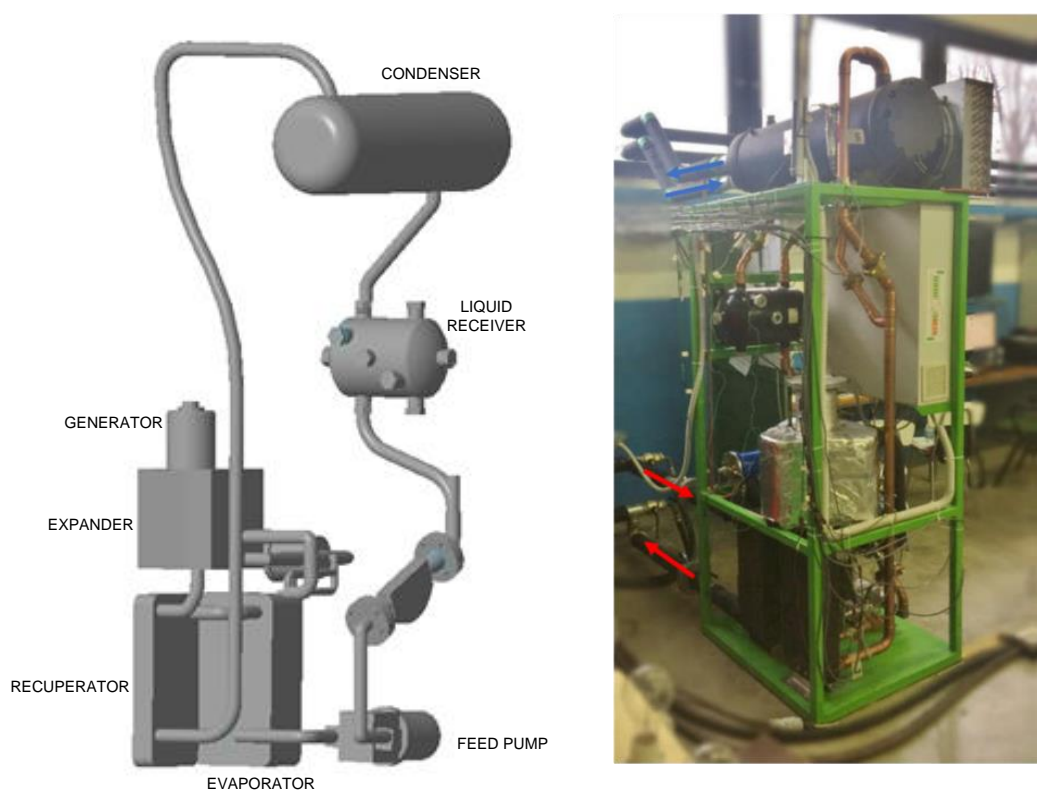

Figure 3 - ORC experimental prototype: a) 3D model, b) photo of the installation 


\section{INSTRUMENTATIONS AND ACQUISITION SYSTEM}

The test bench has been instrumented with a number of sensors in order to investigate the system behavior under different steady-state operating conditions. The main specifics of the measurement devices are listed in Table 1 with their associated Component Off-the-Shelf (COTS) accuracy values.

To measure extensively the performance of the system and its main units, temperature and pressure sensors have been placed at the inlet and outlet of each component of the ORC circuit (see Figure 1). T-type thermocouples with mineral insulating sheath are used to measure the temperature. Absolute ceramic pressure transducers have been installed, with a measuring range of $0-10$ bar for the low-pressure line, and 0-30 bar for the high-pressure line (300 Hz response frequency). Moreover, one thermocouple has been positioned between the expander surface and the wool panel, and one on the panel external surface; these data were used in a simplified heat transfer model to evaluate the thermal losses through the expander walls. All thermocouples and pressure transducers have been calibrated at the laboratory in their operating ranges. A Coriolis flow meter was used to acquire the mass flow rate and density of the working fluid at the pump inlet.

Two printed circuit boards (PCB), made of voltage and current transducers, are used to acquire the three-phase electric power produced by the generator and absorbed by the pump motor. The generator frequency is also obtained from the analysis of the alternating current signal, allowing to determine the expander shaft rotational speed.

On water side, K-type thermocouples are used to measure hot and cold-water temperatures at the inlet and outlet pipes of the evaporator and the condenser. Two magnetic flow meters acquire the volumetric flow rate of water at the inlet of the evaporator and of the condenser.

Table 1 - Acquisition system specifications

\begin{tabular}{|c|c|c|c|c|c|c|}
\hline $\begin{array}{l}\text { Physical } \\
\text { quantity }\end{array}$ & $\begin{array}{l}\text { Layout point } \\
\text { (Figure 1) }\end{array}$ & Sensor & $\begin{array}{c}\text { Calibration } \\
\text { range }\end{array}$ & Output signal & $\begin{array}{c}\text { COTS } \\
\text { accuracy* }\end{array}$ & Input module \\
\hline $\begin{array}{c}\text { ORC } \\
\text { Temperatures }\end{array}$ & $\begin{array}{c}2,2,3,4,5 \\
6,8,9\end{array}$ & T-type thermocouple & $0-90{ }^{\circ} \mathrm{C}$ & $\pm 80 \mathrm{mV}$ & $\pm 0.5^{\circ} \mathrm{C}$ & \multirow{3}{*}{$\begin{array}{c}\text { NI9213- } \\
\text { Thermocouple } \\
\text { input }\end{array}$} \\
\hline $\begin{array}{c}\text { Hot water } \\
\text { temperatures }\end{array}$ & 10,11 & \multirow{2}{*}{ K-type thermocouple } & \multirow{2}{*}{$0-90{ }^{\circ} \mathrm{C}$} & \multirow{2}{*}{ $\pm 80 \mathrm{mV}$} & \multirow{2}{*}{ $\pm 0.5^{\circ} \mathrm{C}$} & \\
\hline $\begin{array}{c}\text { Cold water } \\
\text { temperatures }\end{array}$ & 12,13 & & & & & \\
\hline ORC & $2,8,9$ & \multirow{2}{*}{ Pressure transducer } & $0-30$ bar & \multirow{2}{*}{$0-5 \mathrm{~V}$} & \multirow{2}{*}{ $\pm 0.25 \% \mathrm{FS}$} & NI9201- \\
\hline Pressures & $3,4,5,6$ & & $0-10$ bar & & & Voltage AI \\
\hline $\begin{array}{l}\text { ORC mass } \\
\text { flow rate }\end{array}$ & \multirow[t]{2}{*}{7} & \multirow{2}{*}{ Coriolis mass flow meter } & $0.05-1.00 \mathrm{~kg} / \mathrm{s}$ & $4-20 \mathrm{~mA}$ & $\pm 0.3 \% \mathrm{RV}$ & \multirow{4}{*}{$\begin{array}{l}\text { NI9203- } \\
\text { Current AI }\end{array}$} \\
\hline ORC density & & & $10-1300 \mathrm{~kg} / \mathrm{m}^{3}$ & $4-20 \mathrm{~mA}$ & $\pm 0.1 \mathrm{~kg} / \mathrm{m}^{3}$ & \\
\hline $\begin{array}{l}\text { Hot water } \\
\text { flow rate }\end{array}$ & 10 & Magnetic flow meter & $0-6.41 / \mathrm{s}$ & $4-20 \mathrm{~mA}$ & $\pm 0.5 \% \mathrm{RV}$ & \\
\hline $\begin{array}{l}\text { Cold water } \\
\text { flow rate }\end{array}$ & 12 & Magnetic flow meter & $0-9.8 \mathrm{l} / \mathrm{s}$ & 4-20 mA & $\pm 0.5 \% \mathrm{RV}$ & \\
\hline $\begin{array}{l}\text { Electric } \\
\text { current and } \\
\text { voltage }\end{array}$ & $\begin{array}{l}\text { Expander } \\
\text { generator and } \\
\text { pump motor } \\
\text { supply lines }\end{array}$ & $\begin{array}{l}\text { PCB mounted Hall effect } \\
\text { voltage and current } \\
\text { transducers }\end{array}$ & $\begin{array}{c}0-400 \mathrm{~V} \\
0-5 \mathrm{~A}\end{array}$ & $0-4 \mathrm{~V}$ & $\begin{array}{l} \pm 0.1 \% \mathrm{RV} \\
\pm 0.2 \% \mathrm{RV}\end{array}$ & $\begin{array}{l}\text { NI9215- } \\
\text { Voltage AI }\end{array}$ \\
\hline
\end{tabular}

*Component Off-the-Shelf (COTS) accuracy: it refers to the instrument accuracy as indicated on the data sheet, before individual calibration or calibration of the measurement chain, see section 5 .

Directly measured data (temperature, pressure and flow rate) are updated with a time step equal to $1 \mathrm{~s}$, while electric current and voltage signals are sampled with a $10 \mathrm{kHz}$ frequency at the expander generator and $50 \mathrm{kHz}$ at the pump motor.

All acquired signals are transmitted to a workstation by a National Instrument FPGA device (CompactRIO). Specific used input modules are listed in Table 1. A dedicated real-time data acquisition software has been developed in the LabVIEW environment to monitor and process all the acquired measurements. It is designed in two sub-programs, named Real-time and Host, running 
in the CompactRIO processor and in the workstation, respectively. The Real-time subprogram executes the signal conditioning, the conversion of the electric analogue signals in the physical quantities, and the adjustment of the measured variables by means of the calibration equations. The equations have been obtained after the calibration process described in the next sections. The Host sub-program contains the user panel of the acquisition software, which displays in real time the measured variables in graphical indicators. It also implements the data processing through the aid of the thermodynamic library CoolProp [31], which is integrated in the software and allows to obtain the real enthalpy values as function of temperature and pressure measured values, for the evaluation of the thermal power rates. Moreover, the Host sub-program displays the thermodynamic states determined in the measuring sections on temperature-entropy and pressure-enthalpy diagrams, thus the thermodynamic cycle can be on-line monitored over the entire experimental test campaign.

\section{STEADY-STATE DETECTION AND PERFORMANCE INDEXES}

\subsection{On-line steady state detection methodology}

In this study, the on-line implementation of the steady-state detection algorithm R-test [32] was experimented. This approach was selected after a comparison against two other methods found in literature, namely the Moving Standard Deviation (MStD) [26] and the Wavelet transform [23], where the R-test demonstrated to be the most effective between the considered procedures, showing a good time response in all the tested conditions as well as the best match with the mean values calculated with the manual identification of the steady-state operation.

It consists in evaluating the variations from the stationary conditions of the process variable trend, through the $R_{\mathrm{i}}$ index, calculated for each $\mathrm{i}$-th process variable; the $R_{\mathrm{i}}$ value is computed in real-time as the ratio of two different estimates of the moving variance of the considered time-series of data; the two estimations are computed by filtering the process variable and its variance with the filtering factors, which are adjustable between 0 and 1 to adapt the sensitivity of the method to the dynamic characteristics of the specific process. The application of the method implies the calibration of the filtering factors, whose values determine the readiness of the index $R_{\mathrm{i}}$ in detecting the variations of the process variable. The values of the filtering factors are taken according to [32].

The $R_{\mathrm{i}}$ values, computed instant by instant, are then plotted versus time and compared to a threshold, $R_{\text {critical. If }} R_{\mathrm{i}}<R_{\text {critical }}$ for a period longer than the minimum required $\left(t_{s s}\right)$, the variable is considered in steady-state conditions. A value of the threshold $R_{\text {critical }}$ must be set for each type of measured quantity, based on the knowledge of the historical data, accounting the maximum acceptable variation around the average value of the interval detected. The maximum acceptable variation is determined according to the set of standard thresholds proposed by Woodland et al. [24], summarized in Table 2. The minimum duration required for the steady-state interval, $t_{\mathrm{ss}}$, is set based on the characteristic times of stabilization of the measured variables, and more specifically, equal to the characteristic time of the slowest variable in achieving the steady-state conditions (typically a fluid temperature, due to the thermal inertia).

Table 2 - Acceptable variation for the steady-state condition according to Woodland et al. [24]

\begin{tabular}{|c|c|}
\hline Measured variable & Maximum acceptable variation \\
\hline Temperature & $\Delta<0.5{ }^{\circ} \mathrm{C}$ \\
\hline Pressure & $\Delta<2 \%$ \\
\hline Mass flow rate & $\Delta<2 \%$ \\
\hline Rotational speed & $\Delta<2 \%$ \\
\hline
\end{tabular}

In comparison with other methods, the R-test presents the advantage of saving only the variables computed at the previous instant, minimizing the memory needed for the algorithm implementation and making it suitable for the on-line application. 
A specific function was developed and integrated in the LabVIEW acquisition software, executing the R-test algorithm in realtime; since the number of measured quantities was rather high, the real-time function is implemented only on the key variables, i.e. hot source and cooling system temperature, expander inlet and outlet pressure and temperature, ORC mass flow rate and expander speed, computing the $R_{i}$ values at the same frequency as the acquisition system $(1 \mathrm{~Hz})$.

\subsection{Performance indexes definition}

Several indexes have been considered to evaluate both single components and system overall performances. Table 3 collects all the investigated indicators. At first, the expander and pump electrical powers $\left(\dot{W}_{\text {exp,el }}\right.$ and $\left.\dot{W}_{\text {exp,pp }}\right)$ are the sum of the three single phases powers, which are computed as the average in $1 \mathrm{~s}$ of the product between the instantaneous current and voltage sine waves values (Eq. 1 and Eq. 4). The expander total efficiency $\left(\eta_{\text {exp }}\right)$, defined in Eq. 2 , is expressed as the ratio of the electrical power output $\left(\dot{W}_{\text {exp,el }}\right)$ and the isentropic power. The filling factor $(F F)$, which indicates the volumetric performance of the expander, is defined as the ratio of the actual volumetric flow rate and the theoretical value (Eq. 3); it is obtained using the expander speed $(N)$, the total displacement $\left(V_{\text {exp }}\right)$ and the specific volume $\left(v_{\text {suc }}\right)$, calculated through the CoolProp thermodynamic library (using temperature and pressure measured values at the expander inlet). Pump performance are accounted with the total efficiency $\left(\eta_{\mathrm{pp}}\right)$, defined in Eq. 6 as the ratio between the hydraulic power $\left(\dot{W}_{\mathrm{pp}, \mathrm{hy}}\right.$, Eq. 5) of the fluid and the electric power absorbed by the pump motor ( $\dot{W}_{\mathrm{pp}, \mathrm{el}}$, Eq. 4).

The thermal power exchanged in the evaporator $\left(\dot{Q}_{\text {ev }}\right)$, in the condenser $\left(\dot{Q}_{\text {cond }}\right)$ and in the recuperator $\left(\dot{Q}_{\text {rec }}\right)$ are calculated according to Eqs 7-9, where the enthalpy values are calculated via CoolProp using measured temperatures and pressures as input. Thermal losses at the heat exchangers have been neglected, as confirmed by measurements not shown in the paper. Superheating and sub-cooling degrees are expressed by Eq. 10 and Eq. 11, respectively, as the difference between the superheating temperature $\left(T_{2}\right)$ and the evaporation temperature $\left(T_{\mathrm{ev}}\right)$, and between the condensation temperature ( $\left.T_{\mathrm{cond}}\right)$ and the sub-cooling temperature $\left(T_{6}\right)$. The saturation temperature values are obtained by means of the CoolProp library using the evaporation and condensation pressure $\left(p_{2}, p_{6}\right)$. The recuperator effectiveness is determined by Eq. 12 , where $\dot{Q}_{r e c}$ is the actual thermal power exchanged and $\dot{Q}_{\infty}$ is the power that would be transferred considering an infinite heat exchange surface, i.e. if the hot fluid outlet temperature achieved the cold fluid inlet temperature.

The back work ratio $(B W R)$ is calculated according to Eq. 13 as the ratio between the pump electric consumption $\left(\dot{W}_{\text {pp,el }}\right)$ and the expander electric power output $\left(\dot{W}_{\text {exp,el }}\right)[4]$. The total ORC gross efficiency $\left(\eta_{\text {ORC,gross }}\right)$ and net efficiency $\left(\eta_{\text {ORC,net }}\right)$ are determined by Eq. 14 and Eq. 15. The Carnot efficiency $\left(\eta_{\text {Carnot }}\right)$, is evaluated for reference purpose by Eq. 16, using the maximum and minimum water temperatures; the second law efficiency $\left(\eta_{I I}\right)$, is also calculated by Eq. 17, as the ratio between the ORC net efficiency and the efficiency of an ideal reversible cycle $\left(\eta_{\mathrm{rrc}}\right)$ (consisting in an isobaric heat absorption, an isentropic expansion and an isothermal compression), which represents a measure of the distance of the actual thermodynamic cycle from the ideal cycle in which thermal power is supplied by a finite heat source with variable temperature [33]. 
Table 3 - Performance indexes

\begin{tabular}{|c|c|c|}
\hline \multicolumn{3}{|c|}{ Expander performance indexes } \\
\hline Expander electrical power [W] & $\dot{W}_{\text {exp,el }}=\overline{l_{1}(t) \cdot v_{1}(t)}+\overline{l_{2}(t) \cdot v_{2}(t)}+\overline{l_{3}(t) \cdot v_{3}(t)}$ & (1) \\
\hline Expander total efficiency [W] & $\eta_{\text {exp }}=\frac{\dot{W}_{\text {exp,el }}}{\dot{m}_{\mathrm{ORC}} \cdot\left(h_{2}-h_{3, i s}\right)}$ & (2) \\
\hline Filling factor $[-]$ & $F F=\frac{\dot{m}_{O R C} \cdot v_{\text {suc }}}{N \cdot V_{\exp }}$ & (3) \\
\hline \multicolumn{3}{|c|}{ Pump performance indexes } \\
\hline Pump electrical power $[\mathrm{W}]$ & $\dot{W}_{\mathrm{exp}, \mathrm{pp}}=\overline{l_{1}(t) \cdot v_{1}(t)}+\overline{l_{2}(t) \cdot v_{2}(t)}+\overline{l_{3}(t) \cdot v_{3}(t)}$ & (4) \\
\hline Pump hydraulic power [W] & $\dot{W}_{\mathrm{pp}, \mathrm{hy}}=\frac{\dot{m}_{\mathrm{ORC}} \cdot\left(p_{8}-p_{6}\right)}{\rho_{7}}$ & $(5)$ \\
\hline Pump total efficiency [-] & $\eta_{\mathrm{pp}}=\frac{\dot{W}_{\mathrm{pp}, \mathrm{hy}}}{\dot{W}_{\mathrm{pp}, \mathrm{el}}}$ & (6) \\
\hline \multicolumn{3}{|c|}{ Heat exchangers indexes } \\
\hline Thermal power $[\mathrm{W}]$ & $\begin{array}{c}\dot{Q}_{\mathrm{ev}}=\dot{m}_{\mathrm{ORC}} \cdot\left(h_{2}-h_{9}\right) ; \dot{Q}_{\text {cond }}=\dot{m}_{\mathrm{ORC}} \cdot\left(h_{5}-h_{6}\right) \\
\dot{Q}_{\mathrm{rec}}=\dot{m}_{\mathrm{ORC}} \cdot\left(h_{3}-h_{4}\right)=\dot{m}_{\mathrm{ORC}} \cdot\left(h_{9}-h_{8}\right)\end{array}$ & $\begin{array}{l}(7),(8) \\
\quad(9)\end{array}$ \\
\hline $\begin{array}{l}\text { Superheating and sub-cooling degree } \\
\qquad\left[{ }^{\circ} \mathrm{C}\right]\end{array}$ & $\Delta T_{\mathrm{SH}}=T_{2}-T_{\mathrm{ev}}\left(p_{\mathrm{ev}}\right) ; \quad \Delta T_{\mathrm{SC}}=T_{\text {cond }}\left(p_{\text {cond }}\right)-T_{6}$ & $(10),(11)$ \\
\hline Recuperator effectiveness [-] & $\eta_{\mathrm{rec}}=\frac{\dot{Q}_{\mathrm{rec}}}{\dot{Q}_{\infty}}=\frac{T_{9}-T_{8}}{T_{3}-T_{8}}$ & $(12)$ \\
\hline \multicolumn{3}{|c|}{ Overall performance indexes } \\
\hline Back Work Ratio [-] & $B W R=\frac{\dot{W}_{\mathrm{pp}, \mathrm{el}}}{\dot{W}_{\mathrm{exp}, \mathrm{el}}}$ & $(13)$ \\
\hline ORC gross and net efficiencies [-] & $\eta_{\mathrm{ORC}, \mathrm{gross}}=\frac{\dot{W}_{\mathrm{exp}, \mathrm{el}}}{\dot{Q}_{\mathrm{ev}}}, \eta_{\mathrm{ORC}, \mathrm{net}}=\frac{\dot{W}_{\mathrm{exp}, \mathrm{el}}-\dot{W}_{\mathrm{pp}, \mathrm{el}}}{\dot{Q}_{\mathrm{ev}}}$ & $(14),(15)$ \\
\hline Carnot efficiency [-] & $\eta_{\text {Carnot }}=1-\frac{T_{\text {cold }}}{T_{\text {hot }}}$ & (16) \\
\hline Second Law efficiency [-] [33] & $\eta_{\mathrm{II}}=\frac{\eta_{\mathrm{ORC}, \text { net }}}{\eta_{\mathrm{rrc}}}=\frac{\eta_{\mathrm{ORC}, \text { net }}}{1-\frac{T_{\mathrm{cold}}}{T_{\mathrm{hot}}-T_{\text {cold }}} \cdot \ln \left(\frac{T_{\mathrm{hot}}}{T_{\text {cold }}}\right)}$ & $(17)$ \\
\hline
\end{tabular}

\section{MEASUREMENT UNCERTAINTY}

The uncertainty evaluation is applied to pressure and temperature measurements. In this section, the contributions to the overall uncertainty such as calibration process, connections, and acquisition devices are taken into account. Calibration procedure, described below, was performed for the overall pressure and temperature measurements chains, in order to reduce and compensate for noise originated from the electric connections. 
Measurement instruments are installed at the inlet and outlet of each component by means of specifically realized taps. In particular, pressure and temperature sensors are installed in the same taps using a tee fitting. In each measurement point, the temperature probe (T-type thermocouples) is mounted according to the straight line of tee connection and the length of the thermocouple sheath (100-mm long, 1.5- $\mathrm{mm}$ diameter) allows the evaluation of the flow temperature in the center of the pipe section. This peculiarity ensures the best and fast response, in term of fluid temperature, avoiding the drawbacks related to the wall-mounting temperature probe characterized by several uncertainties such as insulation and conduction issues, delay, coupling with the environment. The connection of the pressure transducer is realized in the $90^{\circ}$-port of the tee allowing the evaluation of pressure value in the same section of the temperature probe. This feature eliminates the uncertainty of enthalpy evaluation due to the different location of pressure and temperature sensors. Considering the pipe diameter, equal to $42 \mathrm{~mm}$, a single pressure tap, instead of the adoption of a piezometer ring, is adopted. This solution, reduce the complexity and the leakages issue of the ORC system without affecting the accuracy of the measurement [34]. Measurement taps were checked to ascertain the absence of burrs or slag and, thus, their contributions to the total error of pressure measurements, which can be remarkable [34], has been neglected.

Each pressure sensor with its correspondent acquisition device has been individually calibrated using a pressure calibrator MicroCal PM200+, representing the in-house laboratory secondary standard which, in turn, is calibrated towards a primary laboratory standard certified in agreement with the Italian Accreditation Body (Accredia). A standard procedure was adopted for the calibration process, consisting in the definition of the first order (linear) calibration curve realized using several pairs of measured pressure and reference pressure values. The Best Straight Line (BSL) was obtained by considering a minimum of 25 independent points. Inaccuracy related to the hysteresis was evaluated by means of a two-way calibration process (from lower to higher-pressure values, and vice-versa), while the temperature effects on the pressure measurement were neglected. In this specific application, the calibration procedure was realized in the ORC laboratory in the same condition of the normal operation of the ORC system.

After this procedure, the type B uncertainty of each pressure measurement is obtained by considering the uncertainty of the primary laboratory standard (that represents the reference uncertainty of the certified laboratory standard) $U_{p, P L S}($ two times the standard deviation value, considered as a Gaussian distribution) and the residual uncertainty value of the pressure measurement chain $E_{p, R}$. The latter value is estimated considering the peak-to-valley amplitude of a set of pressure values obtained during 10 minutes of constant pressure input (generated and controlled by the MicroCal PM200+) and it is considered to have a rectangular probability distribution. This procedure also allows the evaluation of the type A uncertainty by estimating the standard deviation (two times the standard deviation value, considered as a Gaussian distribution) of the set of data $U_{p, \sigma}$. The size of the sample (about 600 pressure measurements) ensures the proper application of the statistic methodology.

Finally, type A and type B contributions are combined by means of Eq. 18 and the final assessment of the pressure measurements extended uncertainty (according to the ISO/IEC Guide 98 and EA-4/02M, the expanded uncertainty is obtained by multiplying the standard uncertainty by the coverage factor $k$ equal to 2 , that corresponds to a confidence level of about $95 \%$ ) is shown in Table 4 for each pressure measurement according to the nomenclature test bench reported in Fig. 1.

$$
U_{\mathrm{p}}=k \sqrt{\left(\frac{U_{\mathrm{p}, \mathrm{PLS}}}{2}\right)^{2}+\left(\frac{E_{\mathrm{p}, \mathrm{R}}}{\sqrt{3}}\right)^{2}+\left(\frac{U_{\mathrm{p}, \sigma}}{2}\right)^{2}}
$$

Table 4 - Individual contribution to overall pressure uncertainty

\begin{tabular}{|l|l|l|} 
Type B uncertainty & Type A uncertainty & Total \\
\hline
\end{tabular}




\begin{tabular}{|c|c|c|c|c|c|}
\hline & & Calibration $U_{\mathrm{p}, \mathrm{PLS}}$ & Residual $E_{\mathrm{p}, \mathrm{R}}$ & Random effects $U_{p, \sigma}$ & $U_{\mathbf{p}}$ \\
\hline \multirow{5}{*}{ 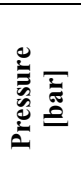 } & 2 & 0.0061 & 0.0051 & 0.009 & 0.012 \\
\hline & 3 & 0.0038 & 0.0024 & 0.003 & 0.006 \\
\hline & 6 & 0.0038 & 0.0040 & 0.003 & 0.007 \\
\hline & 8 & 0.0038 & 0.0043 & 0.002 & 0.007 \\
\hline & 9 & 0.0061 & 0.0097 & 0.008 & 0.015 \\
\hline
\end{tabular}

A similar procedure is applied to the temperature sensors. The thermocouples are calibrated in a thermostatic static furnace (Isotech Jupiter 650 ) that introduces an estimated error of $E_{\mathrm{T}, \mathrm{F}}$ equal to $0.10 \mathrm{~K}$ (related to the non-ideal uniform temperature of the bath, estimated by the manufacturer and ensured by the metallic holder able to fix the position of the probe inside the furnace) and a first order (linear) calibration curve was obtained in the range of $288 \mathrm{~K}-365 \mathrm{~K}$. The reference temperature was obtained with a Pt100 Class A thermistor (4-wire) coupled with the Microcal 200+ calibrator. This reference temperature chain represents the in-house laboratory secondary standard calibrated towards a primary laboratory standard certified in agreement with the Italian Accreditation Body (Accredia), characterized by an uncertainty equal to $U_{\mathrm{T}, \mathrm{PLS}}=0.09 \mathrm{~K}$. Type A and Type B uncertainty contributions are established by means of a similar procedure used for pressure sensors (the estimation of the peak-to-valley amplitude $E_{T, R}$ and a standard deviation $U_{T, \sigma}$ of a set of temperature values obtained during 10 minutes of constant temperature input). With this strategy, the individual errors due to the voltage measuring system, ice-point reference and the thermometer used for calibration was included in Type B uncertainty. In particular, the ice-point reference is provided by the data acquisition system and, usually, it is affected by the ambient temperature. Since this calibration procedure was carried out in the same conditions of which the ORC and the acquisition systems operate, the inaccuracies related to the icepoint reference values were included in the calibration process.

Finally, the uncertainty related to the installation and radiation effects [35] was neglected considering the similar temperature between the duct walls and the thermocouples tip. Table 5 summarizes the uncertainty values related to each temperature measurement, according to the nomenclature proposed in Fig. 1 and calculated according to the early mentioned procedure. The final temperature uncertainty is calculated according to the following equation

$$
U_{\mathrm{T}}=k \sqrt{\left(\frac{U_{\mathrm{T}, \mathrm{PLS}}}{2}\right)^{2}+\left(\frac{E_{\mathrm{T}, \mathrm{F}}}{\sqrt{3}}\right)^{2}+\left(\frac{E_{\mathrm{T}, \mathrm{R}}}{\sqrt{3}}\right)^{2}+\left(\frac{U_{\mathrm{T}, \sigma}}{2}\right)^{2}}
$$

Table 5 - Individual contribution to overall temperature uncertainty

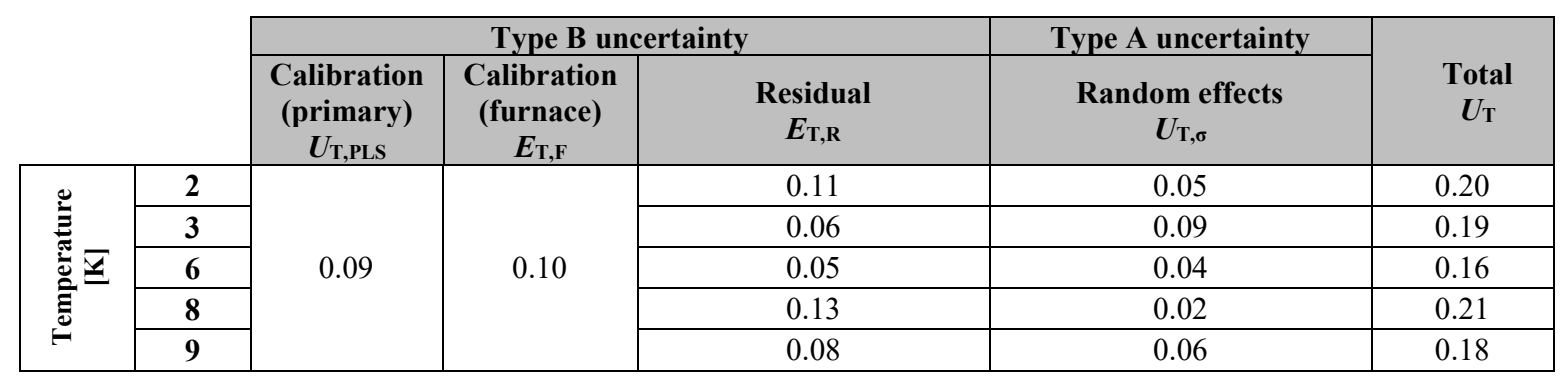

\section{EXPERIMENTAL CAMPAIGN RESULTS AND DISCUSSION}

\subsection{Test set points and operating conditions}

The tests were conducted imposing different set points of the water temperature at the evaporator inlet (hot source temperature, $\left.T_{\text {hot }}\right)$. The hot source temperature was varied in the range $65-85^{\circ} \mathrm{C}$. The effect of the cooling system temperature ( $T_{\text {cold }}$ ) was also investigated, as the tests were performed in two different ambient conditions (namely in winter and summer 
time), affecting the condenser inlet temperature, which varied between $18^{\circ} \mathrm{C}$ and $27{ }^{\circ} \mathrm{C}$. The hot source and cooling system water flow rates have been kept constant close to $2.6 \mathrm{l} / \mathrm{s}$ and $2.8 \mathrm{l} / \mathrm{s}$, respectively.

For each value of $T_{\text {hot, }}$ the ORC motor pump speed $\left(N_{\mathrm{pp}}\right)$ was varied by step, obtaining a total number of 37 steady-state operating points. Table 6 summarizes the test operating conditions.

Table 6 - Test operating conditions and set points

\begin{tabular}{|c|c|c|}
\hline \multirow{2}{*}{$\boldsymbol{T}_{\text {hot }}\left[{ }^{\circ} \mathrm{C}\right]$} & \multicolumn{2}{|c|}{$\boldsymbol{N}_{\text {pp }}[\mathbf{r p m}]$} \\
\cline { 2 - 3 } & Winter tests $\left(T_{\text {cold }} \approx 18^{\circ} \mathrm{C}\right)$ & Summer tests $\left(T_{\text {cold }}=22-27^{\circ} \mathrm{C}\right)$ \\
\hline 65 & $270-450$ & 405 \\
\hline 70 & - & $300-525$ \\
\hline 75 & $375-600$ & $375-525$ \\
\hline 85 & $270-600$ & $300-675$ \\
\hline
\end{tabular}

The ORC pump rotating speed was varied between $270 \mathrm{rpm}$ and $675 \mathrm{rpm}$. Since the pump is of positive displacement type, the mass flow rate can be expressed as function of the rotating speed, according to the following equation:

$$
\dot{m}_{\mathrm{ORC}}=\frac{N_{\mathrm{pp}}}{60} \cdot \rho_{\mathrm{in}} \cdot V_{\mathrm{pp}, \mathrm{eff}}
$$

where $N_{\mathrm{pp}}$ is the pump speed (determined from the supply current signal frequency), $\rho_{\text {in }}$ is the fluid density at the inlet section of the pump, and $V_{\mathrm{pp} \text {,eff }}$ is the actual pump swept volume in a revolution. A direct correlation between the pump speed and the ORC mass flow rate has been experimentally observed (Figure 4). At constant pump speed, the ORC mass flow rate assumes slight different values due to the variation of the fluid density and of the actual pump swept volume (as explained in Eq. 18). More in details, the fluid density, which is acquired by the Coriolis flow meter, reveals modest variations depending on the condensation pressure values, and accounts for a variation of only $1 \%$ of the $\dot{m}_{\mathrm{ORC}}$ value, at constant speed; the actual pump volume, instead, causes a variation up to the $9 \%$ of the mass flow rate value.

The ORC mass flow rate affects the evaporation pressure $\left(p_{2}\right)$ of the cycle (Figure 5), which varied between 11 bar and 19 bar, as the ORC flow rate increases from $0.05 \mathrm{~kg} / \mathrm{s}$ to $0.14 \mathrm{~kg} / \mathrm{s}$. On the contrary, the condensation pressure $\left(p_{3}\right)$ is barely influenced by the ORC flow rate (with increments lower than $5 \%$ versus $\dot{m}_{\mathrm{ORC}}$, not visible in Fig. 5 ), as it depends for the most part on the cooling system temperature (which is constant in the operating conditions showed in Fig. 5). This behavior results, at given cooling system conditions, in a roughly linear dependence of the pressure ratio $\left(p_{2} / p_{3}\right)$ from the ORC mass flow rate.

Figure 6 reports the superheating degree as function of the mass flow rate, for different values of hot source temperature (i.e. of superheating temperature $T_{2}$, since the difference $\tau_{1}=T_{\text {hot }}-T_{2}$ is quite constant and low, as showed in heat exchangers results section). The values of superheating degree ranged between $10^{\circ} \mathrm{C}$ and $40{ }^{\circ} \mathrm{C}$ in the test performed. As expected, at given water temperature the superheating degree decreases with the mass flow rate; indeed, $\dot{m}_{\mathrm{ORC}}$ affects the evaporation pressure $\left(p_{\mathrm{ev}}=p_{2}\right.$, Fig. 5$)$ and thus temperature $\left(T_{\mathrm{ev}}\right)$, while at constant values of mass flow rate, $\Delta T_{\mathrm{SH}}$ increases versus $T_{\text {hot }}\left(T_{2}\right)$. The effect of the pump speed on the superheating degree, at constant superheating temperature $\left(T_{2}\right)$, is also visible in Figure 7, where the thermodynamic cycles obtained from two steady-state operating conditions are compared on the temperature entropy $(T-s)$ diagrams, for a hot source temperature of $75^{\circ} \mathrm{C}$ and a cold sink temperature close to $18{ }^{\circ} \mathrm{C}$ in both cases. In particular, the comparison reveals that the increment of the pump rotating speed from $450 \mathrm{rpm}$ to $600 \mathrm{rpm}$ leads to the increase of the evaporation pressure from 14.5 bar to 17.0 bar (pressure ratio from 2.4 to 2.8 ), reducing the superheating degree from $20.0^{\circ} \mathrm{C}$ to $13.5^{\circ} \mathrm{C}$. 


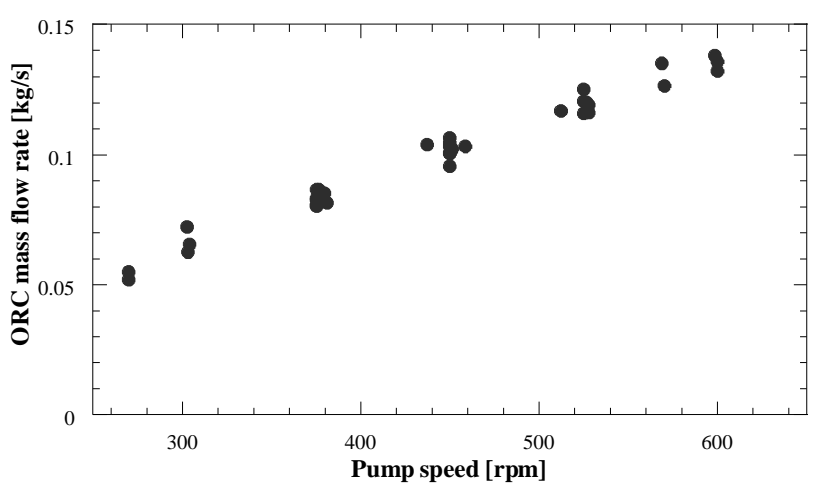

Figure 4 - Organic fluid measured mass flow rate vs. pump rotational speed

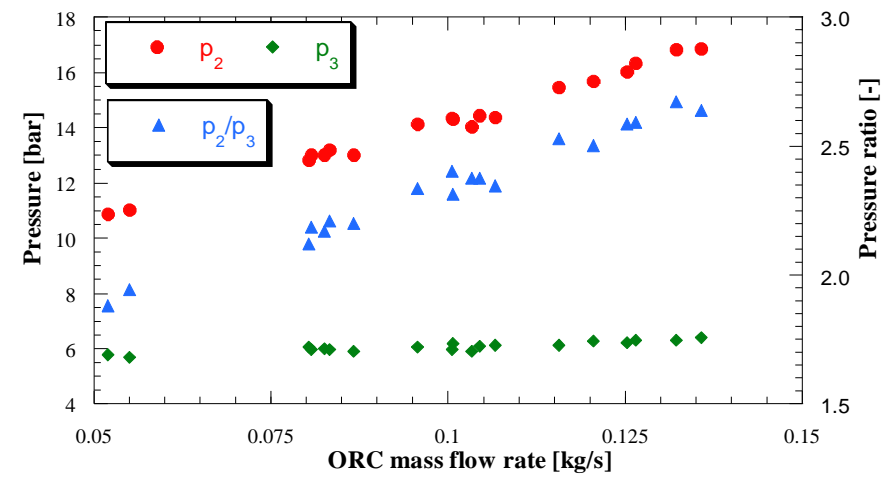

Figure 5 Expander inlet and outlet pressure and pressure ratio vs. ORC mass flow rate

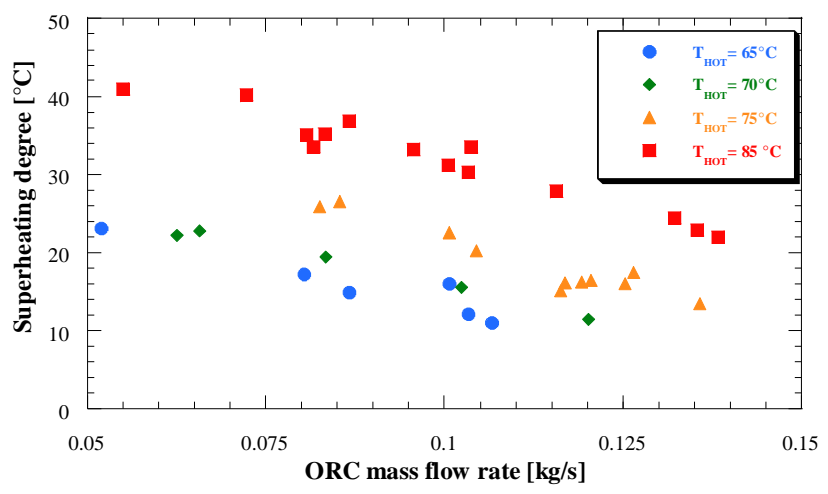

Figure 6 - Superheating degree vs. ORC mass flow rate, for different $\mathrm{T}_{\text {hot }}$ values
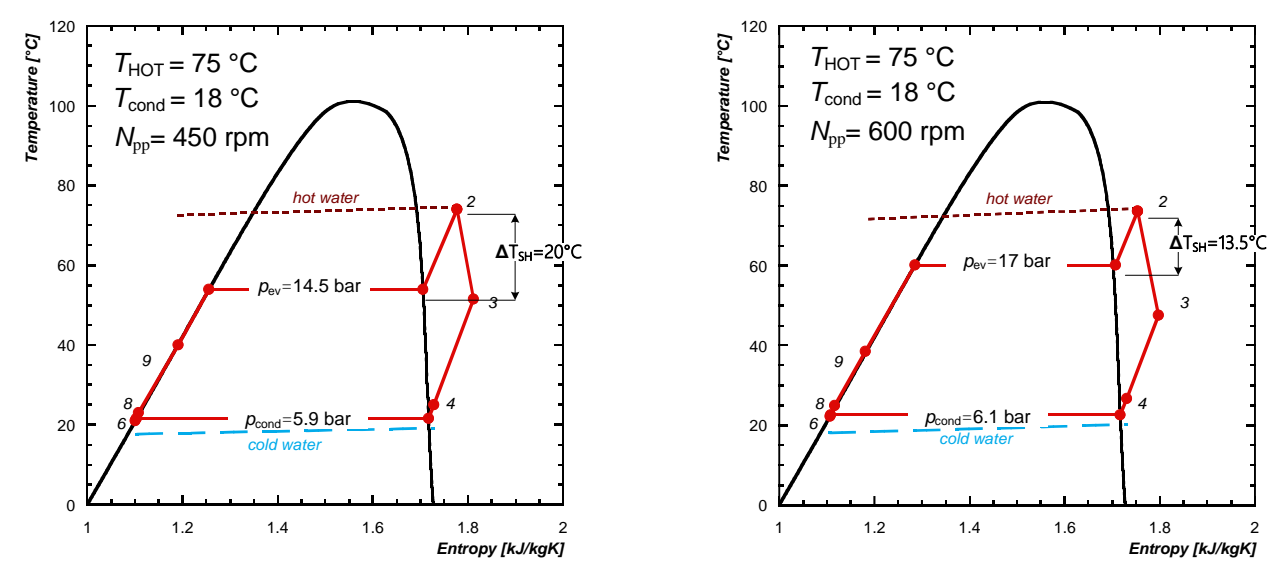

Figure 7 - Thermodynamic cycle on temperature-entropy diagram, for two operating conditions

\subsection{Expander performance}

In Figure 8 the electrical power is reported as function of the superheating degree, for two condensation pressure values equal to 6 bar and 7 bar. The power output increases with the hot water temperature and decreases with the superheating degree; this corresponds, at given hot source temperature, to a dependency from the evaporation pressure (and from the ORC mass flow rate). Moreover, the higher condensation pressure penalizes the produced power, since it reduces the expansion ratio. The electric power output varied from $250 \mathrm{~W}$ to $1200 \mathrm{~W}$. 
As mentioned in section 2, the electric load implemented in this test bench does not set the expander rotational speed to a constant value, and the system was not equipped with a speed regulator. The expander rotational speed is therefore the result of the torque balance at the shaft. Since the expander is a displacement machine, its rotational speed depends on the working fluid volumetric flow rate flowing through the cylinders, which is a function of the mass flow rate (set by the pump speed) and of the density at the expander inlet (function of the working fluid pressure and temperature). It was observed that the expander rotating speed increases with the pump speed and it depends also on the load impedance value (Figure 9). At constant pump speed indeed, the expander rotates faster if the number of electric loads activated is lower, or if the load impedance is higher. The minimum and the maximum values of the expander speed were $320 \mathrm{rpm}$ and $1100 \mathrm{rpm}$, achieved respectively for 5 and 1 activated loads. In Figure 10 the electric power output is plotted as function of the expander speed and of the number of loads. The power-speed curve of the expander presents three different trends, corresponding to the different values of the load impedance activated. At constant rotational speed, the power produced is higher for higher number of loads (or for lower load impedance value). At fixed impedance, the electrical output increases with the expander rotational speed; the figure also shows that the slope of the curves at constant number of loads increases with the load impedance decrease (or with the number of loads increase).

The expander total efficiency $\left(\eta_{\text {exp }}\right)$, evaluated as indicated in Eq. 2, can be also expressed as the product of a thermal isentropic efficiency, $\eta_{i s, t h}$, and the electro-mechanical efficiency, $\eta_{e m}$, as specified below:

$$
\eta_{\text {exp }}=\eta_{\text {is,th }} \cdot \eta_{\text {em }}=\frac{\dot{W}_{\text {exp }, \text { th }}}{\dot{m}_{\mathrm{ORC}} \cdot\left(h_{2}-h_{3, \text { is }}\right)} \cdot \frac{\dot{W}_{\text {exp }, \mathrm{el}}}{\dot{W}_{\text {exp,th }}}
$$

where $\dot{W}_{\text {exp,th }}=\dot{m}_{\mathrm{ORC}} \cdot\left(h_{2}-h_{3}\right)$ is the expander actual thermodynamic power. In Figure 11 , the efficiency is plotted as function of the pressure ratio $\left(p_{2} / p_{3}\right)$. It shows a quite constant trend with modest variations between $42 \%$ and $38 \%$. The penalization of $\eta_{\text {exp }}$ is determined (in addition to the fluid-dynamic losses and irreversibilities) also by the generator efficiency, which can be lower than the value declared by the manufacturer ( $90 \%$ ), since the generator works at lower rotating speed and power output than the nominal values (1800 rpm and $3 \mathrm{~kW}$, respectively).

The filling factor $(F F)$ trend is reported in Figure 12, showing a dependence from the pressure ratio and from the number of activated electric loads. At constant number of loads, the value of $F F$ decreases with the pressure ratio increment, the latter corresponding, in a first approximation, to the increase of the rotating speed of the pump (see Fig. 5) and, as observed in Fig. 9, of the expander; at fixed pressure ratio (thus at fixed pump speed), the $F F$ becomes higher with the number of loads increase (which determines a lower value of the expander rotating speed). Summarizing, a better volumetric performance is observed for the total number of loads activated (5 loads, 15 light bulbs), with a maximum value close to 0.9 at a pressure ratio of 1.8 , decreasing down to 0.6 at a pressure ratio of 2.6 .

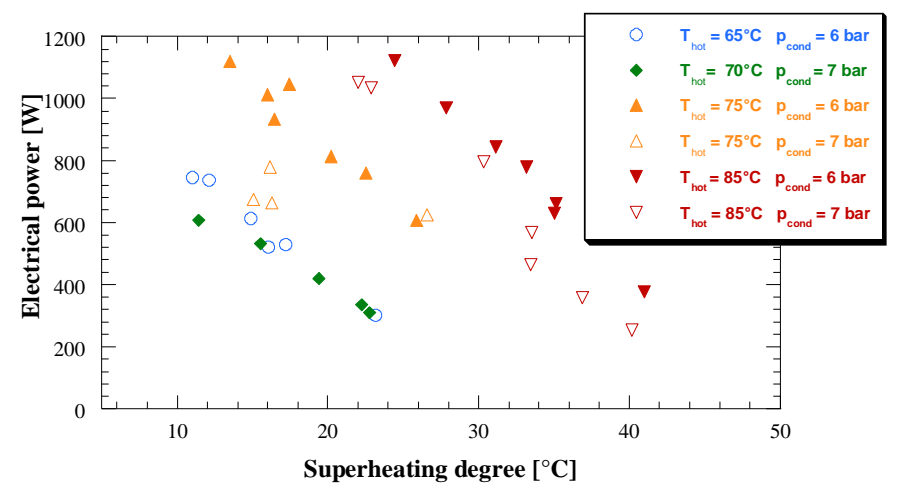

Figure 8 - Expander electrical power vs. superheating degree, for different $T_{\text {hot }}$ and $p_{\text {cond }}$ values 


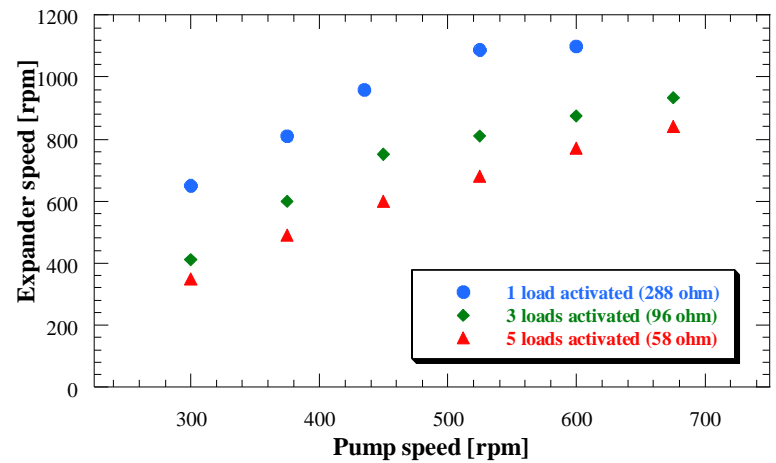

Figure 9 - Expander rotational speed vs. pump speed

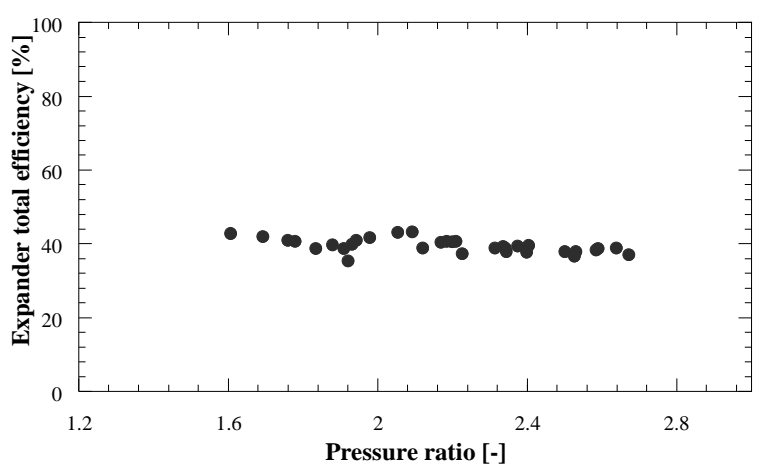

Figure 11 - Expander efficiency vs pressure ratio

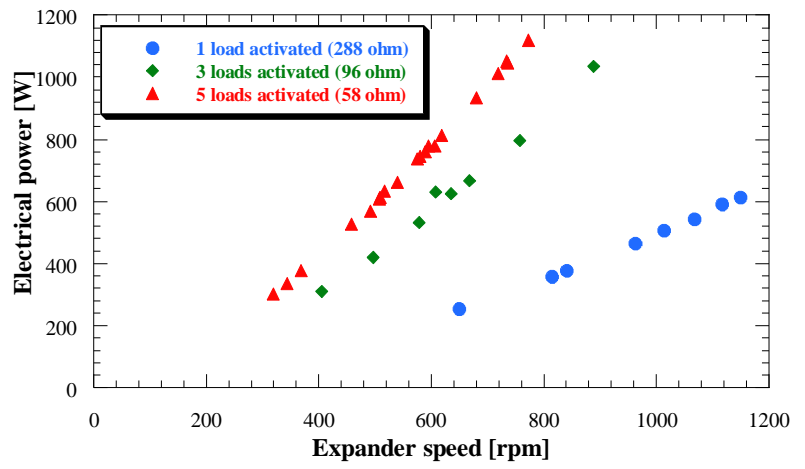

Figure 10 - Expander electrical power vs. rotational speed

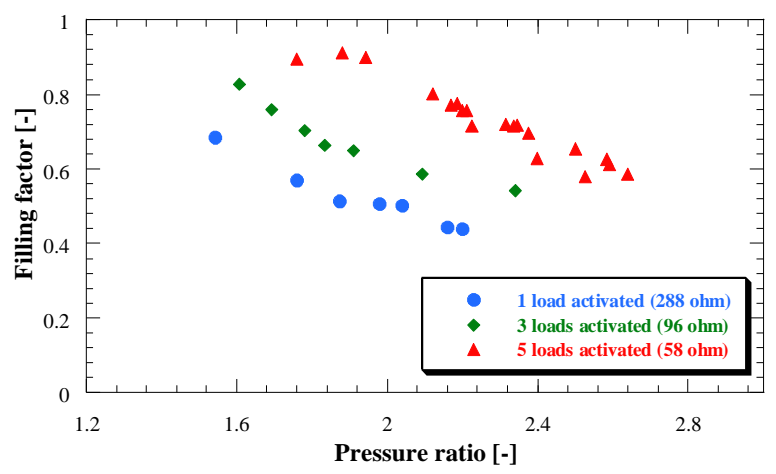

Figure 12 - Expander filling factor vs pressure ratio

\subsection{Pump performance}

With such a limited system power output, the pump performance becomes of crucial importance; in fact, the auxiliary consumption can absorb a significant fraction of that power, questioning the effective convenience in adopting similar configuration as a solution for micro-scale heat recovery.

The absorbed electric power, the hydraulic power and the total efficiency of the pump are reported in Figure 13, as function of the pump rotating speed, showing increasing trends. The pump hydraulic power and the electric power varied in the range $20-160 \mathrm{~W}$ and $200-700 \mathrm{~W}$, respectively, for a pump speed going from $270 \mathrm{rpm}$ to $675 \mathrm{rpm}$. The total efficiency, which takes into account also the mechanical and electrical power losses, ranged from $10 \%$ to $19 \%$, increasing with the rotational speed. At high speed, phenomena of instability were observed, due to two-phase conditions at the pump inlet: the Coriolis flow meter indicates two-phase fluid, no longer being able to measure correctly mass flow rate and density. As better specified in next section, in all the tested working points, the organic fluid at the pump inlet presents a sub-cooling degree close to $0{ }^{\circ} \mathrm{C}$, neither depending on ORC mass flow rate nor on cooling system water temperature. At higher fluid speed, pressure losses increase, eventually causing the saturation of the working fluid at pump inlet and thus the instability of cycle. The main effects of this event are the sudden collapse of the ORC mass flow rate, of the evaporation pressure and, consequently, of the expander speed and power output, since the pressure difference is no longer sufficient to produce mechanical work. 


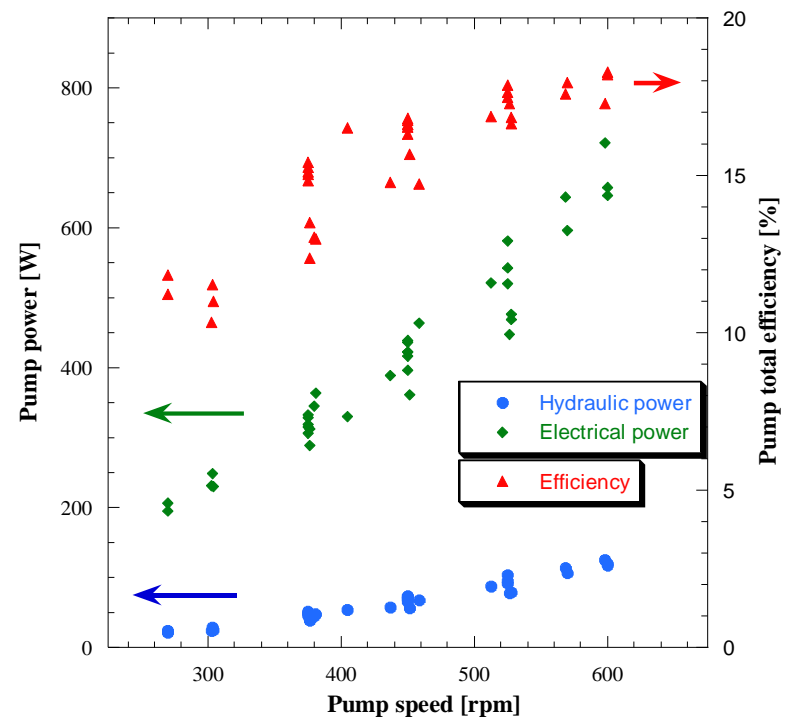

Figure 13 - Pump hydraulic power, electrical power and total efficiency vs. rotational speed

\subsection{Heat exchangers}

In Figure 14, the thermal power rates exchanged in the evaporator $\left(\dot{Q}_{\mathrm{ev}}\right)$ and in the condenser $\left(\dot{Q}_{\text {cond }}\right)$ are reported. The transferred thermal power is a linear function of the ORC mass flow rate, increasing with the latter up to almost $30 \mathrm{~kW}$, just below the nominal power of the boiler. Figure 15 shows the thermal power transferred at the recuperator $\left(\dot{Q}_{\text {rec }}\right)$, which varied between $1 \mathrm{~kW}$ and $4 \mathrm{~kW}$, being a considerable fraction of the thermal input $\dot{Q}_{\mathrm{ev}}(10-15 \%)$.

Figure 16 shows a comparison on the T-Q diagram for the evaporator, in two steady-state operating points, at same mass flow rate and evaporation pressure, and different hot source temperature $\left(75^{\circ} \mathrm{C}\right.$ and $\left.85^{\circ} \mathrm{C}\right)$. The heat transfer analysis reveals a very low value of the terminal temperature difference $\tau_{1}$ (difference between the water inlet and the ORC outlet temperatures, $\left.\tau_{1}=T_{\text {hot }}-T_{2}\right)$, around $1{ }^{\circ} \mathrm{C}$. On water side, the temperature difference between inlet and outlet keeps lower than $2{ }^{\circ} \mathrm{C}$ for most of the tests conducted, due to the considerable gap between the flow rate of the working fluid and the one of the water, which was 10-20 times higher.

Besides, the pinch point PP (i.e. the point on the T-Q diagram with the minimum difference between the evaporation temperature and the hot water temperature, see Fig. 16) shifts to the water outlet as Thot rises from $75^{\circ} \mathrm{C}$ to $85^{\circ} \mathrm{C}$; thus, the superheating power $\left(\dot{Q}_{\mathrm{SH}}=\dot{m}_{\mathrm{ORC}} \cdot\left(h_{2}-h_{\mathrm{VAP}}\right)\right)$ increases to the detriment of the economizing power $\left(\dot{Q}_{\mathrm{ECO}}=\dot{m}_{\mathrm{ORC}} \cdot\right.$ $\left.\left(h_{\mathrm{LIQ}}-h_{9}\right)\right)$, the total power exchanged being constant. This circumstance occurs because the evaporator inlet temperature $\left(T_{9}\right)$ increases. 
On the other hand indeed, the increment of the recuperator thermal power is observed (Figure 17, referred to the same operating conditions displayed for the evaporator): at constant conditions for mass flow rate and condensing pressure, the recuperator vapour inlet temperature (i.e. the expander outlet, $T_{3}$ ) increases while the outlet temperature (i.e. the condenser inlet, $\left.T_{4}\right)$ keeps constant, as the superheating temperature $\left(T_{2}\right)$ rises from $75^{\circ} \mathrm{C}$ to $85^{\circ} \mathrm{C}$. On liquid side, the raise of the thermal power results in the increase of the evaporator inlet temperature $\left(T_{9}\right)$. This behaviour is generically illustrated in Figure 15, which shows the dependence of the recuperator thermal power ( $\dot{Q}_{\mathrm{rec}}$, Eq. 9) from hot source temperature and ORC mass flow rate. At constant mass flow rate (corresponding in first approximation to constant thermal power input, $\dot{Q}_{\text {ev }}$ ), the recuperator thermal power increases with the hot source temperature increment; the latter, indeed, affects the expander outlet temperature $\left(T_{3}\right.$, correspondent to the recuperator inlet temperature), increasing the recuperator enthalpy difference, $\Delta h_{\text {rec }}=h_{3}\left(T_{3}, p_{3}\right)-h_{4}\left(T_{4}, p_{4}\right)$, the outlet enthalpy $h_{4}$ remaining quite constant. The recuperator effectiveness, expressed by Eq. 12 , was roughly constant, around $60 \%$, in all the tested conditions.

The heat transfer diagrams for the condenser (Figure 18) show the influence of cold water temperature on the condensation temperature (and pressure) of the cycle. Both cases present a sub-cooling degree close to zero, revealing that almost all the thermal power of the water is used for the condensation of the organic fluid. This condition, which increases the risk of cavitation of the ORC pump, occurs in all the performed tests, the sub-cooling not being greater than $1{ }^{\circ} \mathrm{C}$. Figure 18 reveals also that the minimum temperature difference between water and working fluid corresponds to the start of the condensation in the heat transfer diagram, as in all the investigated operating conditions. This temperature difference keeps quite constant close to a value of $2^{\circ} \mathrm{C}$.

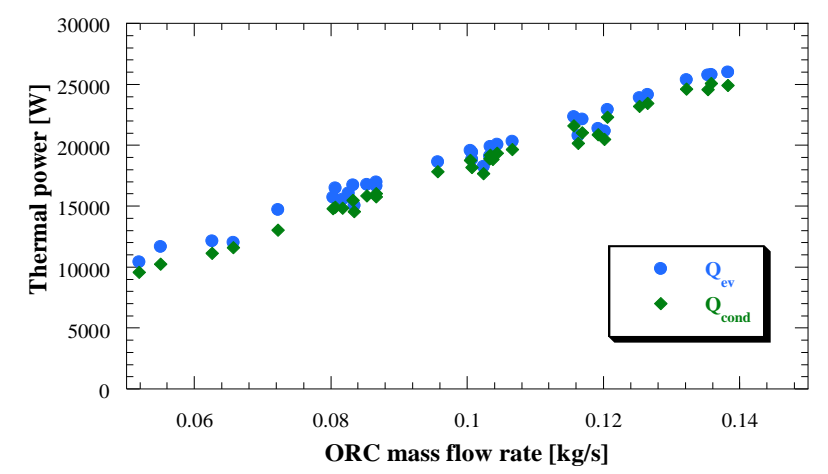

Figure 14 - Evaporator and condenser thermal powers vs. ORC mass flow rate

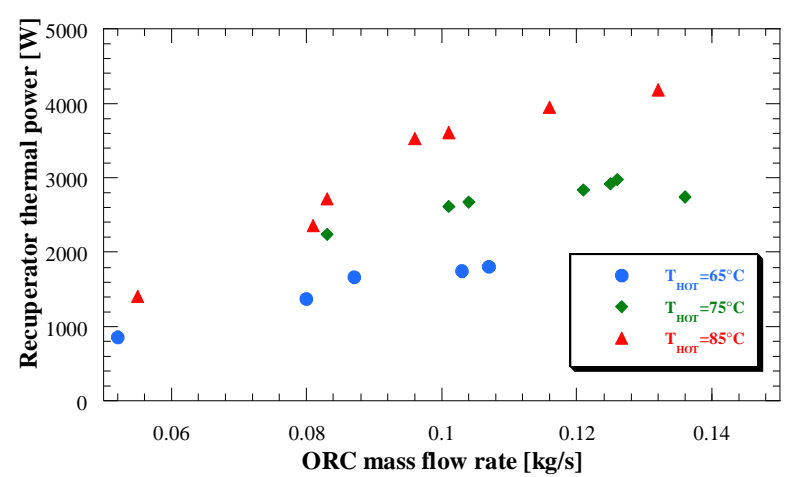

Figure 15 - Recuperator thermal power vs. ORC mass flow rate, for different hot source temperature values 

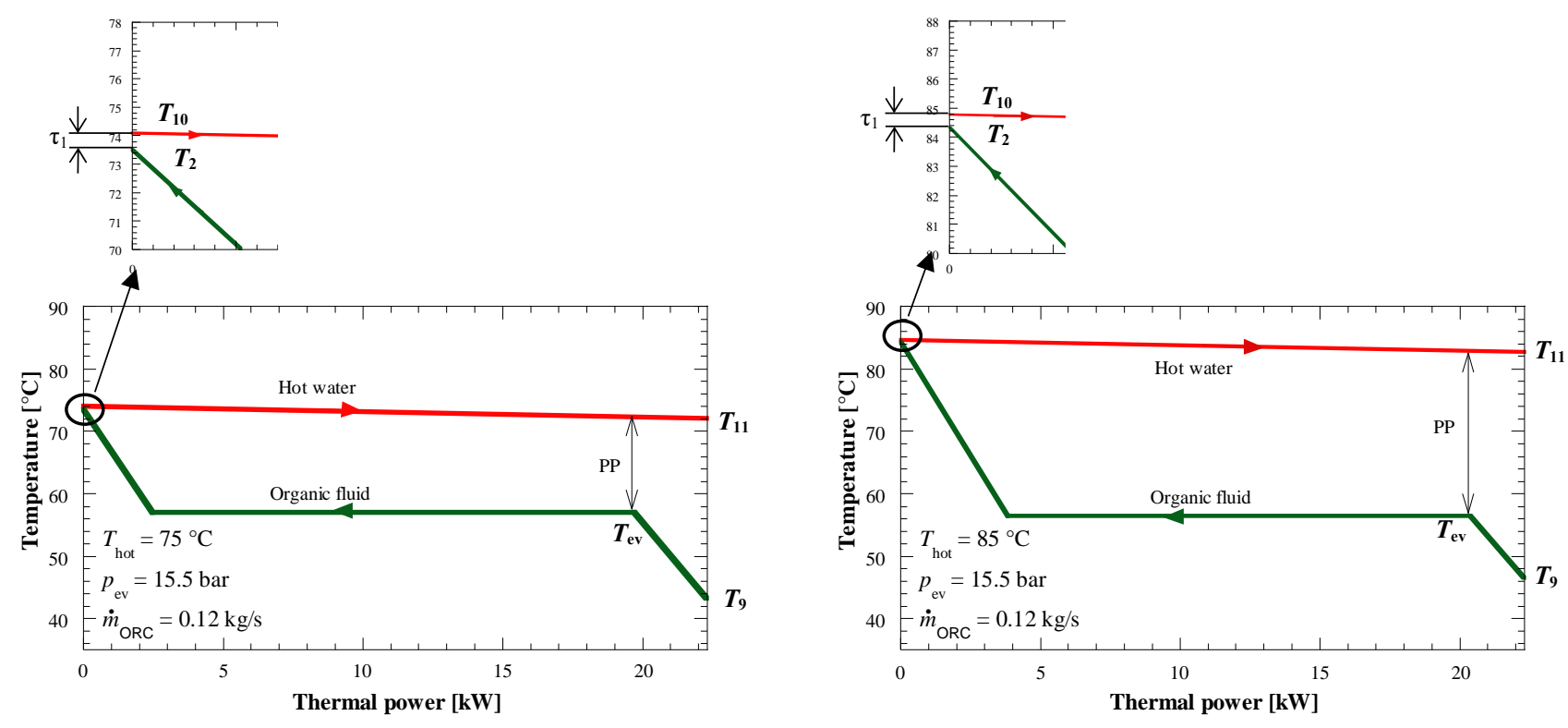

Figure 16 - Heat transfer diagram for the evaporator: effect of the hot source temperature.
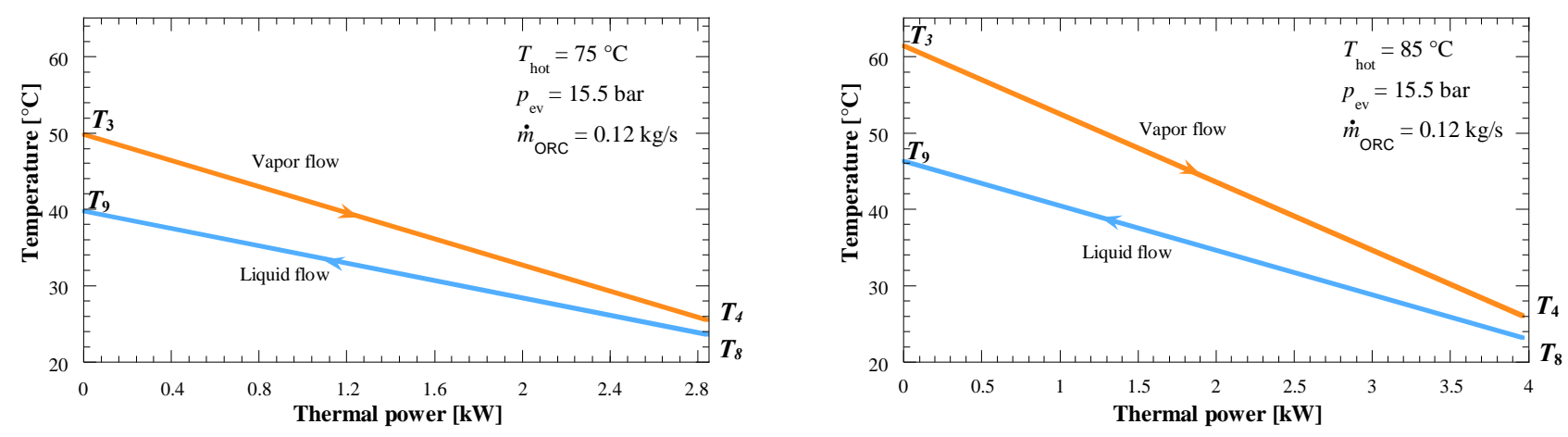

Figure 17 - Heat transfer diagram for the recuperator: effect of the hot source temperature.
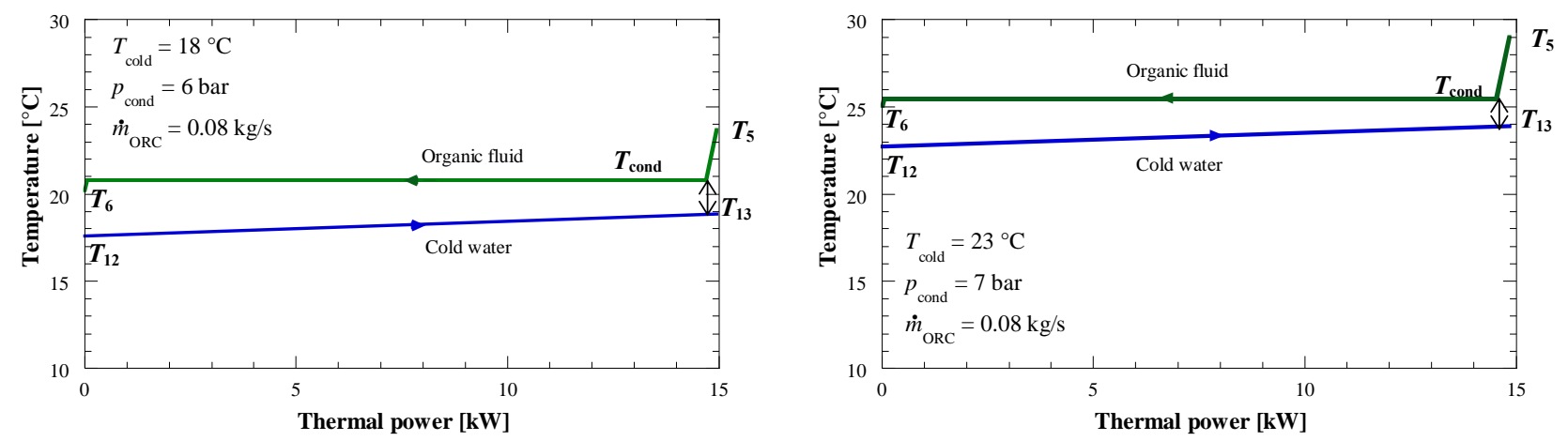

Figure 18 - Heat transfer diagram for the condenser: effect of the cooling system temperature. 


\subsection{Overall performances}

In Figure 19 the overall system gross and net efficiencies are plotted versus the pressure ratio. A maximum value equal to $4.5 \%$ and of $2.2 \%$ was achieved for the gross and the net efficiency, respectively. The impact of the auxiliaries consumption on system performance is reported in Figure 20, where the back work ratio (BWR), defined by Eq. 13, is displayed as function of the pressure ratio. For a pressure ratio higher than 2, the BWR keeps between $50 \%$ and $60 \%$, while it becomes greater than $70 \%$ for the lowest pressure ratio tested values. These results demonstrate the significance of the pump consumption in the overall system performance, suggesting that a detailed assessment on the pump selection and dimensioning is strictly required for power system of such size and features at the design stage. Indeed, compared to the other common fluid suitable for low temperature processes, the adoption of the R134a as working fluid implies lower achievable net efficiencies, partly due to a large pressure rise in the feed pump which increases the power consumption [36]. Moreover, the evaluation of the Carnot efficiency $\left(\eta_{\text {Carnot }}\right.$, Eq. 16) points out how the system performances are penalized by the low temperature difference between hot source and cold sink (ranging between $40^{\circ} \mathrm{C}$ and $65^{\circ} \mathrm{C}$ ), which limits the efficiency of the equivalent Carnot cycle to values between $12 \%$ and $20 \%$. The second law efficiency $\left(\eta_{I I}\right.$, Eq. 17) revealed a preponderant dependence from the cooling system temperature, while the hot source temperature effect is less significant (for Thot increment, the $\eta_{I I}$ value slightly decreases); the $\eta_{\mathrm{II}}$ value keeps lower than $15 \%$ for high $T_{\text {cold }}$ conditions $\left(\approx 23^{\circ} \mathrm{C}\right.$, summer tests), while at low $T_{\text {cold }}\left(\approx 18{ }^{\circ} \mathrm{C}\right.$, winter tests) $\eta_{\text {II }}$ maintains between $18 \%$ and $23 \%$. Finally, Figure 21 represents the energy flows in a Sankey diagram, for one steady-state operating point. As illustrated, almost all the power introduced is discharged to the cold sink. The irreversibility includes also the thermal losses through the expander surfaces, which have been estimated below $50 \mathrm{~W}$, thanks to the thermal insulation. The diagram highlights the substantial penalization due to the pump consumption, which absorbs the $50 \%$ of the gross expander electric output in the considered test.

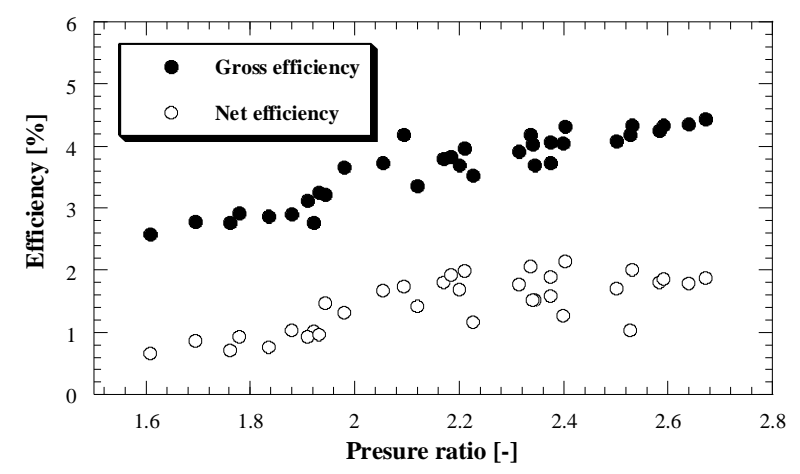

Figure 19 - ORC gross and net efficiency vs. pressure ratio

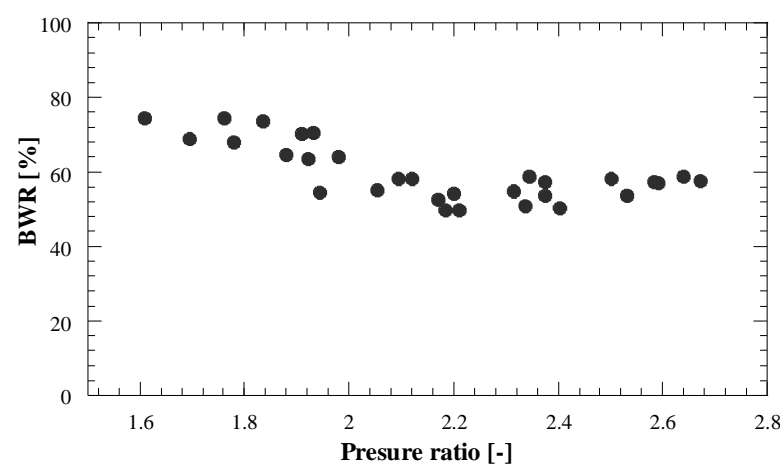

Figure 20 - Back work ratio vs. pressure ratio 


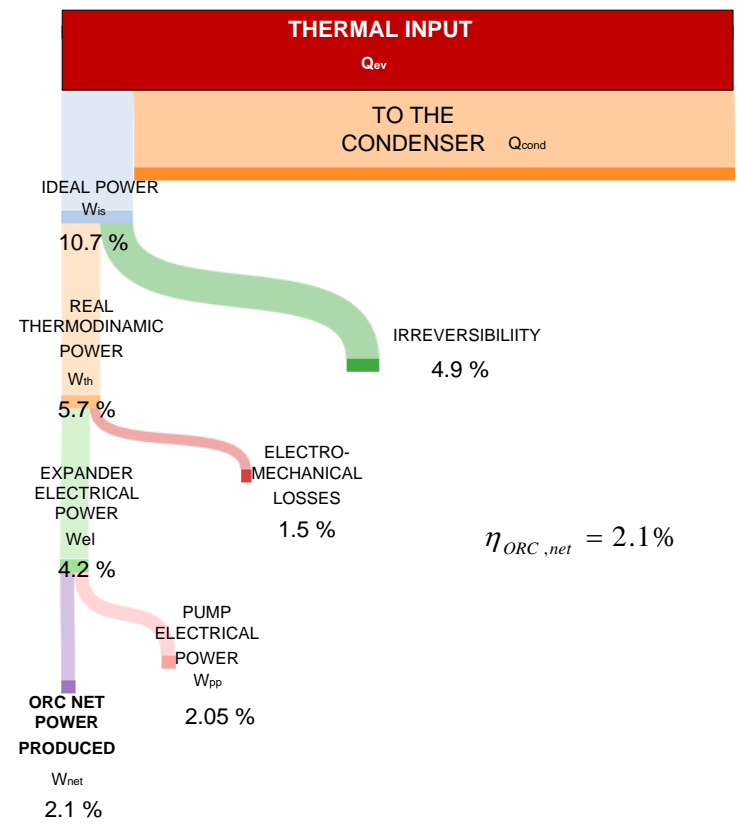

Figure 21 - Sankey diagram at the following test conditions: $T_{\text {hot }}=85^{\circ} \mathrm{C} ; p_{e v}=14.1 \mathrm{bar} ; p_{\text {cond }}=6.0 \mathrm{bar} ; \quad \dot{m}_{\text {ORC }}=0.095 \mathrm{~kg} / \mathrm{s}$

\section{CONCLUSIONS}

This paper presents an experimental study on a micro-ORC energy system suitable for low-temperature heat recovery. The peculiarity of this system is the expansion machine, which is a radial piston prototype, more often adopted with high temperature thermal sources. The other components are a gear-type feed pump with variable speed, two brazed plate heat exchangers as evaporator and recuperator and a shell and tube condenser. The heat source is made by water heated by an electric boiler with nominal power of $32 \mathrm{~kW}$; the cooling system is water at ambient conditions pumped from a well; a variable resistive load is connected to the generator of the expander. The facility is fully equipped with thermocouples, pressure transducers, flow sensors and power meters for the complete characterization of the system performances, and an acquisition software developed in LabVIEW environment. The test campaign was conducted at different hot source temperature set points and varying the ORC's feed pump speed.

The experimental results show the dependence of the organic fluid mass flow rate and evaporation pressure from the pump rotational speed, while the condensing pressure is mainly affected by the cooling system temperature. At fixed hot source temperature, the superheating degree is a linear function of the mass flow rate. The expander rotational speed was imposed by the flow rate of the working fluid, thus by the pump frequency, and by the number of electric loads activated. For the expander total efficiency, a maximum value close to $43 \%$ was obtained, slightly decreasing with the expander speed and pressure ratio increase; the filling factor showed a dependence from the pressure ratio and from the number of activated loads, revealing better expander volumetric performance for the maximum number of loads. The gross electrical power output varied between $250 \mathrm{~W}$ and $1200 \mathrm{~W}$, increasing, at constant hot source temperature, with the superheating degree decrease (i.e. with the evaporation pressure increment), showing a dependence also from the number of loads activated. The pump performances, evaluated in terms of hydraulic and electrical power, showed increasing trend versus the pump speed, with a total efficiency varying between $10 \%$ and $20 \%$. The feed pump consumed a large part of the power produced, as the back work ratio ranges between $50 \%$ and $75 \%$, decreasing with the pressure ratio increment. This result confirms the importance of an accurate design and sizing of the pump for micro-scale ORCs, also in terms of the pump motor, in order to reduce to a 
minimum the impact of the auxiliary systems on the overall performance. Finally, the gross and net cycle efficiencies are presented, achieving maximum values of $4.5 \%$ and $2.2 \%$, respectively. Due to the low value of the total efficiency compared to traditional heat conversion technologies, the diffusion of such systems must go through the economical sustainability of the installation costs, as well as the widespread promotion of decentralized energy generation techniques and of solutions with low environmental impact.

\section{ACKNOWLEDGMENTS}

The authors would like to thank StarEngine S.r.I. for the technical support during the performed test campaign. Gratitude must also be expressed to Dr. Eng. Valentina Orlandini for her precious contribution to this work.

\section{REFERENCES}

[1] Dong L., Liu H., Riffat S. Development of small-scale and microscale biomass-fuelled chp systems - a literature review. Applied Thermal Engineering, vol. 29, issue 11 (2009) 2119-2126. DOI: 10.1016/j.applthermaleng.2008.12.004.

[2] Landelle A., Tauveron N., Haberschill P., Revellin R., Colasson S. Organic Rankine cycle design and performance comparison based on experimental database. Applied Energy, vol. 204 (2017), 1172-1187. DOI: 10.1016/j.apenergy.2017.04.012.

[3] Lemort V., Guillaume L., Legros A., Declaye S., Quoilin S. A comparison of piston, screw and scroll expanders for small scale Rankine cycle systems. In Proceedings of the 3rd International Conference on Microgeneration and Related Technologies, 2013. [4] Quoilin S., Van Den Broek M., Declaye S., Dewallef P., Lemort V. Techno-economic survey of Organic Rankine Cycle (ORC) systems. Renewable and Sustainable Energy Reviews, vol. 22 (2013) 168-186. DOI: 10.1016/j.rser.2013.01.028.

[5] Abadi G.B., Yun E., Kim K.C. Experimental study of a 1 kw organic Rankine cycle with a zeotropic mixture of R245fa/R134a. Energy, vol. 93 (2015) 2363 - 2373 DOI: 10.1016/j.energy.2015.10.092.

[6] Ziviani D., James N.A., Accorsi F.A., Braun J.E., Groll E.A. Experimental and numerical analyses of a 5 kWe oil-free open-drive scroll expander for small-scale organic Rankine cycle (ORC) applications. Applied Energy vol. 230 (2018) 1140 - 1156. DOI: 10.1016/j.apenergy.2018.09.025.

[7] Ayachi F., Ksayer E.B., Neveu P., Zoughaib A. Experimental investigation and modeling of a hermetic scroll expander. Applied Energy, vol. 181 (2016) 256-267. DOI: 10.1016/j.apenergy.2016.08.030

[8] Yun E., Kim D., Yoon S.Y., Kim K.C. Experimental investigation of an organic Rankine cycle with multiple expanders used in parallel. Applied Energy, vol. 145 (2015) 246-254. DOI: 10.1016/j.apenergy.2015.02.022.

[9] Ziviani D., Gusev S., Lecompte S., Groll E.A., Braun J.E., Horton W.T., van den Broek M., De Paepe M. Characterizing the performance of a single-screw expander in a small-scale organic Rankine cycle for waste heat recovery. Applied Energy, vol. 181 (2016) 155-170. DOI: 10.1016/j.apenergy.2016.08.048.

[10] Torregrosa A., Galindo J., Dolz V., Royo-Pascual L., Haller R., Melis J. Dynamic tests and adaptive control of a bottoming organic Rankine cycle of IC engine using swash-plate expander. Energy Conversion and Management, vol. 126 (2016) $168-176$. DOI: 10.1016/j.enconman.2016.07.078.

[11] Oudkerk J.F., Dickes R., Dumont O., Lemort V. Experimental performance of a piston expander in a small-scale organic Rankine cycle. J F Oudkerk et al 2015 IOP Conf. Ser.: Mater. Sci. Eng. 90 012066. DOI: 10.1088/1757-899X/90/1/012066.

[12] Dumont O., Parthoens A., Dickes R., Lemort V. Experimental investigation and optimal performance assessment of four volumetric expanders (scroll, screw, piston and roots) tested in a small-scale organic Rankine cycle system. Energy (2018), DOI: 10.1016/j.energy.2018.06.182.

[13] Hou X., Zhang H., Yu F., Liu H., Yang F., Xu Y., Tian Y., Li G. Free piston expander-linear generator used for organic Rankine cycle waste heat recovery system. Applied Energy, vol. 208 (2017) 1297-1307. DOI: 10.1016/j.apenergy.2017.09.024.

[14] Tian Y., Zhang H., Li G., Hou X., Yu F., Yang F., Yang Y., Liu Y. Experimental study on free piston linear generator (FPLG) used for waste heat recovery of vehicle engine. Applied Thermal Engineering, vol. 127 (2017) 184-193. DOI: 10.1016/j.applthermaleng.2017.08.031.

[15] Park B.-S., Usman M., Imran M., Pesyridis A. Review of Organic Rankine Cycle experimental data trends. Energy Conversion and Management, vol. 173 (2018) 679-691. DOI: 10.1016/j.enconman.2018.07.097.

[16] Yamada N., Watanabe M., Hoshi A. Experiment on pumpless Rankine-type cycle with scroll expander, Energy, vol. 49 (2013) 137-145, DOI: 10.1016/j.energy.2012.10.027. 
[17] Jiang L., Lu H.T., Wang L.W., Gao P., Zhu F.Q., Wang R.Z., Roskilly A.P. Investigation on a small-scale pumpless Organic Rankine Cycle (ORC) system driven by the low temperature heat source. Applied Energy, vol. 195 (2017) $478-486$. DOI: 10.1016/j.apenergy.2017.03.082.

[18] Quoilin S., Lemort V., Lebrun J. Experimental study and modeling of an Organic Rankine Cycle using scroll expander. Applied Energy, vol. 87, issue 4 (2010) 1260-1268. DOI: 10.1016/j.apenergy.2009.06.026.

[19] Reid A.D. Low temperature power generation using HFE-7000 in a Rankine cycle, Master thesis, San Diego State University, 2010.

[20] Landelle A., Tauveron N., Revellin R., Haberschill P., Colasson S., Roussel V. Performance investigation of reciprocating pump running with organic fluid for organic Rankine cycle. Applied Thermal Engineering, vol. 113 (2017) 962-969. DOI: 10.1016/j.applthermaleng.2016.11.096.

[21] Cao S., Rhinehart R.R. An efficient method for on-line identification of steady state. Journal of Process Control, 5(6):363374, 1995. DOI: 10.1016/0959-1524(95)00009-F.

[22] Narasimhan S., Kao C. S., Mah R. S. H. Detecting changes of steady states using the mathematical theory of evidence. AlChE Journal, vol. 33, issue 11 (1987) 1930-1932. DOI: 10.1002/aic.690331125.

[23] Jiang T., Chen B., He X., Stuart P. Application of steady-state detection method based on wavelet transform. Computers \& Chemical Engineering, vol. 27, issue 4 (2003) 569-578. DOI: 10.1016/S0098-1354(02)00235-1.

[24] Woodland B. J., Braun J. E., Groll E. A., Horton W. T. Experimental Testing of an Organic Rankine Cycle with Scroll-type Expander. In International Refrigeration and Air Conditioning Conference at Purdue, July 2012.

[25] Lecompte S. Performance Evaluation of Organic Rankine Cycle Architectures: Application to Waste Heat Valorisation. PhD. Thesis, 2016.

[26] Kim M., Ho Yoon S., Domanski P. A., Payne W. V. Design of a steadystate detector for fault detection and diagnosis of a residential air conditioner. International Journal of Refrigeration, vol. 31, issue 5 (2008) 790-799, DOI: 10.1016/j.ijrefrig.2007.11.008.

[27] Li X., Shu G., Tian H., Shi L., Huang G., Chen T., Liu P. Preliminary tests on dynamic characteristics of a CO2 transcritical power cycle using an expansion valve in engine waste heat recovery. Energy, vol. 140, Part 1 (2017) 696-707. DOI: 10.1016/j.energy.2017.09.022.

[28] Bianchi M., Branchini L., De Pascale A., Orlandini V., Ottaviano S., Pinelli M., Spina P.R., Suman A. Experimental Performance of a Micro-ORC Energy System for Low Grade Heat Recovery. Energy Procedia, vol. 129 (2017), 899-906. DOI: 10.1016/j.egypro.2017.09.096.

[29] Zampieri G. "CLOSED-CYCLE PLANT." U.S. Patent No. 20,160,032,786. 4 Feb. 2016.

[30] Declaye S., Quoilin S., Guillaume L., Lemort V. Experimental study on an open-drive scroll expander integrated into an ORC (Organic Rankine Cycle) system with R245fa as working fluid. Energy, vol. 55 (2013) 173-183. DOI: 10.1016/j.energy.2013.04.003.

[31] Bell I.H., Wronski J., Quoilin S., Lemort V. Pure and pseudo-pure fluid thermophysical property evaluation and the opensource thermophysical property library CoolProp. Ind. Eng. Chem. Res; vol. 53 issue 6 (2014) 498-508. DOI: 10.1021/ie4033999.

[32] Cao S., Rhinehart R. R. Critical values for a steady-state identifier. Journal of Process Control, vol. 7, issue 2 (1997) 149-152, DOI: 10.1016/S0959-1524(96)00026-1

[33] Bianchi, M., and A. De Pascale. Bottoming cycles for electric energy generation: parametric investigation of available and innovative solutions for the exploitation of low and medium temperature heat sources. Applied Energy, vol. 88, issue 5 (2011) 1500-1509. DOI: 10.1016/j.apenergy.2010.11.013.

[34] Franklin R.E., Wallace J.M. Absolute measurements of static-hole error using flush transducers Journal of Fluid Mechanics, vol. 42, issue 1 (1970) 33-48. DOI: 10.1017/S0022112070001052.

[35] Benedict R. P., 1984, “Fundamentals of Temperature, Pressure, and Flow Measurements", 3rd Edition, John Wiley and Sons, Inc., New York, USA.

[36] Uusitalo A., Honkatukia J., Turunen-Saaresti T., Grönman A. Thermodynamic evaluation on the effect of working fluid type and fluids critical properties on design and performance of Organic Rankine Cycles. Journal of Cleaner Production, vol. 188 (2018) 253-263. DOI: 10.1016/j.jclepro.2018.03.228. 


\section{Figure Captions}

Figure 1 - Schematic of the test bench layout

Figure 2 StarEngine prototypal piston expander [26]

Figure 3 - ORC experimental prototype: a) 3D model, b) photo of the installation

Figure 4 - Organic fluid measured mass flow rate vs. pump rotational speed

Figure 5 Expander inlet and outlet pressure and pressure ratio vs. ORC mass flow rate

Figure 6 - Superheating degree vs. ORC mass flow rate, for different Thot values

Figure 7 - Thermodynamic cycle on temperature-entropy diagram, for two operating conditions

Figure 8 - Expander electrical power vs. superheating degree, for different $T$ hot and $p_{c}$ values

Figure 9 - Expander rotational speed vs. pump speed

Figure 10 - Expander electrical power vs. rotational speed

Figure 11 - Expander efficiency vs pressure ratio

Figure 12 - Expander filling factor vs pressure ratio

Figure 13 - Pump hydraulic power, electrical power and total efficiency vs. rotational speed

Figure 14 - Evaporator and condenser thermal powers vs. ORC mass flow rate

Figure 15 - Recuperator thermal power vs. ORC mass flow rate, for different hot source temperature values

Figure 16 - Heat transfer diagram for the evaporator: effect of the hot source temperature.

Figure 17 - Heat transfer diagram for the recuperator: effect of the hot source temperature.

Figure 18 - Heat transfer diagram for the condenser: effect of the cooling system temperature.

Figure 19 - ORC gross and net efficiency vs. pressure ratio

Figure 20 - Back work ratio vs. pressure ratio

Figure 21 - Sankey diagram at the following test conditions: $T_{\text {hot }}=85{ }^{\circ} \mathrm{C} ; p_{e v}=14 \mathrm{bar} ; \dot{m}_{O R C}=0.095 \mathrm{~kg} / \mathrm{s}$.

\section{Table Captions}

Table 1 - Acquisition system specifications

Table 2 - Acceptable variation for the steady-state condition according to Woodland et al. [22]

Table 3 - Performance indexes

Table 4 - Individual contribution to overall pressure uncertainty

Table 5 - Individual contribution to overall temperature uncertainty

Table 6 - Test operating conditions and set points 